\title{
Remedios contra la pobreza. Trabajo indígena y producción de riqueza en la amazonia portuguesa, siglo XVIII
}

\author{
Patricia Melo Sampaio \\ Universidad Federal del Amazonas (Brasil) \\ pasampaio@horizon.com.br
}

\begin{abstract}
Resumen $^{1}$
El objetivo de este artículo es tratar de establecer las líneas generales de la organización de la producción de riqueza en el Grão-Pará durante el período pombalino, teniendo en cuenta a los múltiples personajes que intervinieron en este proceso: indios, mestizos, esclavos y libres que vivieron inmersos en diferentes actividades, trabajando para su sustento y también para el de sus señores. Es importante señalar que uno de los argumentos centrales para la incorporación de los indios al mundo colonial era su destino como mano de obra necesaria al funcionamiento de la economía. Disputas interminables marcaron las relaciones entre los diferentes agentes coloniales por su control y los resultados de la economía dependieron del éxito de esta incorporación. Los indios fueron el verdadero "remedio para la pobreza” en Grão-Pará.
\end{abstract}

Palabras clave: AMAZONIA BRASILERA, PERÍODO POMBALINO, INDIOS, MANO DE OBRA, SIGLO XVIII.

\begin{abstract}
The purpose of this article is to establish the general outlines of the organization of the production of wealth in the Grão-Pará during the Pombal period, taking into account the various characters intervening in the process: indians, mestizos, slaves, and freemen that immersed themselves in a diversity of activities for their own sustenance and that of their lords. It is important to point out that one of the central arguments for the incorporation of indians into the colonial world was their role as labor in the economy. Relationships between the different colonial agents were marked by constant disputes
\end{abstract}

Ese artículo tiene como base un capítulo de la tesis de Doctorado en Historia (Universidad Federal Fluminense, Río de Janeiro, Brasil) y los resultados del proyecto de investigación "Políticas indígenas e indigenistas en Grão-Pará, siglos XVIII y XIX” (CNPq/MCT). 
over their control, and economic results depended on their succesful incorporation. Thus, indians were a true "remedy against poverty” in Grão-Pará.

Key Words: BRASILIAN AMAZONY, POMBAL PERIOD, INDIAN LABOR, $18^{\mathrm{TH}}$ CENTURY.

En la segunda mitad del siglo XVIII, la ocupación de los territorios que ahora corresponden a la amazonia brasileña estaba relativamente consolidada en la perspectiva de la corona portuguesa. Por un lado, las posiciones vagas en la frontera con las tierras de España estaban camino a una resolución con la aplicación del Tratado de Madrid (1750). Por otro lado, un grupo de medidas intentaban una reorientación en la política metropolitana con relación al estado de Grão-Pará y Maranhão (1750-1774)², siguiendo las nuevas pautas establecidas en el transporte y los negocios portugueses después de la asunción de Don José I al trono y, con él, la de Sebastião José de Carvalho e Melo, Marqués de Pombal.

La política portuguesa en ese período (que se conocerá en la historiografía como el "período pombalino") estaba basada en los principios de la Ilustración. En general, podemos destacar el fortalecimiento del poder de la corona, el incentivo a las prácticas agrícolas y mercantiles y la reducción del poder de la Iglesia. En la amazonia portuguesa, los lineamientos de esa política presentaron algunas especificidades: la penetración mercantilista del Estado en las actividades económicas, con la creación de la Compañía de Comercio de Grão-Pará e Maranhão; el incentivo oficial al mestizaje y, finalmente, el tema indigenista ${ }^{3}$.

La amazonia portuguesa tenía una economía inclinada al uso del trabajo forzado de los indios garantizado por los instrumentos legales de la esclavitud, hasta ese momento bajo el control misionero. La expulsión de los religiosos de la Compañía de Jesús era de importancia estratégica para garantizar la aplicación de las nuevas disposiciones políticas. Esa medida fue tomada a continuación de la secularización de las misiones y la declaración de la Ley de Libertad de los Indios (1755).

Esa última acción hizo empeorar la controversia alrededor del asunto de la mano de obra, que había sido un problema crónico para la administración portuguesa en el área. La ambigüedad de la legislación en cuanto a la libertad o esclavitud de los indios marcó el período anterior a la aplicación de la política pombalina. Sin embargo, en este

2 El estado de Grão-Pará y Maranhão y el estado de Brasil formaron la América portuguesa. Es importante registrar que en ese momento y hasta la llegada de la familia real a Brasil (1808), no existió una administración centralizada en la colonia y los estados se dirigían directa y separadamente a Lisboa para tratar de sus asuntos. De manera que la expresión "amazonia portuguesa” corresponde a los territorios actuales de los estados brasileños de Pará, Amapá, Amazonas, Roraima y Rondônia.

3 Heloísa Belloto, “Pombal - Marquês de”, en Dicionário da História da Colonização Portuguesa no Brasil, ed. Beatriz N. Silva (Lisboa: Verbo, 1994), 645-648. 
nuevo contexto, el esfuerzo por “aportuguesar” la región pasaría ahora no solo por la garantía de la libertad de los indios, entendidos como vasallos del rey, sino también por la aplicación de un instrumento protector de las poblaciones indígenas aldeanas: el Directorio que se debe observar en las poblaciones de los indios de Pará e Maranhão (1757-1798). Esa legislación incidió en los más diversos niveles de la vida socioeconómica, cultural y política de los indios y es considerada como uno de los instrumentos más ambiciosos de la política pombalina en el esfuerzo por aportuguesar el área ${ }^{4}$.

Partiendo de esa perspectiva, el objetivo de este artículo es tratar de establecer las líneas generales de la organización de producción de riqueza en el Grão-Pará pombalino, considerándola como el telón esencial para una correcta aprehensión de los múltiples personajes que intenta poner delante de la escena: los indios, los mestizos, los esclavos y los libres, que vivieron inmersos en diferentes actividades, trabajando para su sustento y también para el de sus señores. En lo que se refiere a los indios, es importante recuperar esos procesos en la medida que uno de los argumentos centrales para su incorporación al mundo colonial era su cometido de proporcionar la mano de obra necesaria al funcionamiento de la economía colonial. Disputas interminables marcaron las relaciones entre los diferentes agentes coloniales por su control y, sin una duda, los resultados de la economía dependieron del éxito de esa incorporación. Los indios eran los verdaderos “remedios para la pobreza” en Grão-Pará.

La presencia de una mano de obra indígena significativa no era exclusiva de la amazonia portuguesa en el período colonial. Lo demuestran, de manera suficiente, los estudios importantes de Stuart Schwartz sobre la economía de azúcar en Bahía ${ }^{5}$ y los de John Monteiro sobre Sao Pablo ${ }^{6}$. Lejos de constituirse en un episodio de corta duración o simplemente en un "comienzo fallido" antes de la introducción de los esclavos africanos, estos trabajos señalan el carácter duradero y el papel clave que tuvo el uso de los indios en los procesos de acumulación internos, destacando el hecho de que el contacto entre europeos e indígenas hizo posible "la creación de categorías y las definiciones sociales y raciales que caracterizarían continuamente la experiencia colonial”7.

La amazonia es la zona de Brasil donde el empleo del trabajo indígena fue más extendido, llegando hasta la segunda mitad del siglo XIX. De esta forma, es posible suponer que su proceso de diferenciación y de jerarquización interna y, por supuesto, la diná-

4 Carlos A. Moreira Neto, Índios da Amazônia: de maioria a minoria (1750-1850) (Petrópolis: Vozes, 1998).

5 Stuart B. Schwartz, Segredos Internos (São Paulo: Companhia das Letras, 1988).

6 John Monteiro, Negros da Terra: índios e bandeirantes nas origens de São Paulo (São Paulo: Companhia das Letras, 1994).

7 Schwartz, Segredos, 57. 
mica entera de la sociedad que allí se construyó estén profundamente influenciados por esta característica estructural ${ }^{8}$.

Más allá de este asunto central, es importante señalar que la economía colonial de Grão-Pará se desplegó en sectores diversificados, pero articulados entre sí. En primer lugar, la extracción de productos de la selva destinados a la exportación, que respondía a unos lazos mercantiles de mayor rentabilidad en el mercado internacional. A pesar de la política pombalina de incentivos a la agricultura, fue el comercio de "drogas del interior” (drogas do sertão) el que dominó las rutas paraenses. La explotación de la selva traerá obreros para el abastecimiento de innumerables canoas hacia el interior, reducirá la producción de alimentos y enriquecerá, en diferentes grados, a directores, cabos, tesoreros y muchos comerciantes.

En segundo lugar, el sector dedicado a la producción de alimentos (el "sustento ordinario") fue muchas veces considerado como deficiente. Aunque el cultivo de géneros exportables como café, algodón, caña de azúcar, puede que no haya superado las cifras de lo que se sacaba de la selva, sin embargo está presente de una manera significativa, aunque los vacíos historiográficos dejen muchas dudas que no permiten una evaluación precisa del sector.

Dejando la magnitud de la producción a un lado, se nota que el comercio fue una constante en Pará. La ruta del interior que vinculaba Pará a Mato Grosso a través del río Madera también fue importante y tuvo la capacidad de establecer vínculos en áreas que a veces se encontraban desconectadas entre sí. La conjunción de esas actividades responderá a la presencia de una élite mercantil importante que progresivamente también extendería sus acciones por el inmenso interior del río Negro, adquiriendo bastantes recursos como para tener esclavos e inmensas propiedades.

Aun con la presencia de inmensos vacíos, el cuadro que surgió de explorar la historiografía local, todavía poco conocida, unir los fragmentos, repasar los análisis e incorporar los nuevos datos, fue el de una sociedad mucho más compleja de lo que se podría suponer a partir del enfoque limitado que la ha definido meramente como una región extractiva.

\section{Las drogas y las canoas del interior: el espacio de la selva}

Las “drogas del interior” hacen referencia a un grupo de productos extraídos de la selva y destinados a la exportación. Incluían frutas, hojas, raíces, resinas y aceites de origen vegetal, empleados en la alimentación, la medicina, la elaboración de tintas, la construcción naval y la fabricación de cuerdas, entre otras aplicaciones. Bajo esta

8 Sobre el uso del trabajo indígena en la amazonia del siglo XIX, véase John Hemming, Amazon Frontier. The Defeat of the Brazilian Indians (London: Macmillan, 1987) y Carlos A. Moreira Neto, "Política indigenista brasileira durante o século XIX” (tesis doctoral, Rio Claro, s. p., 1971). 
Figura 1

Casa de las indias de Monte Alegre

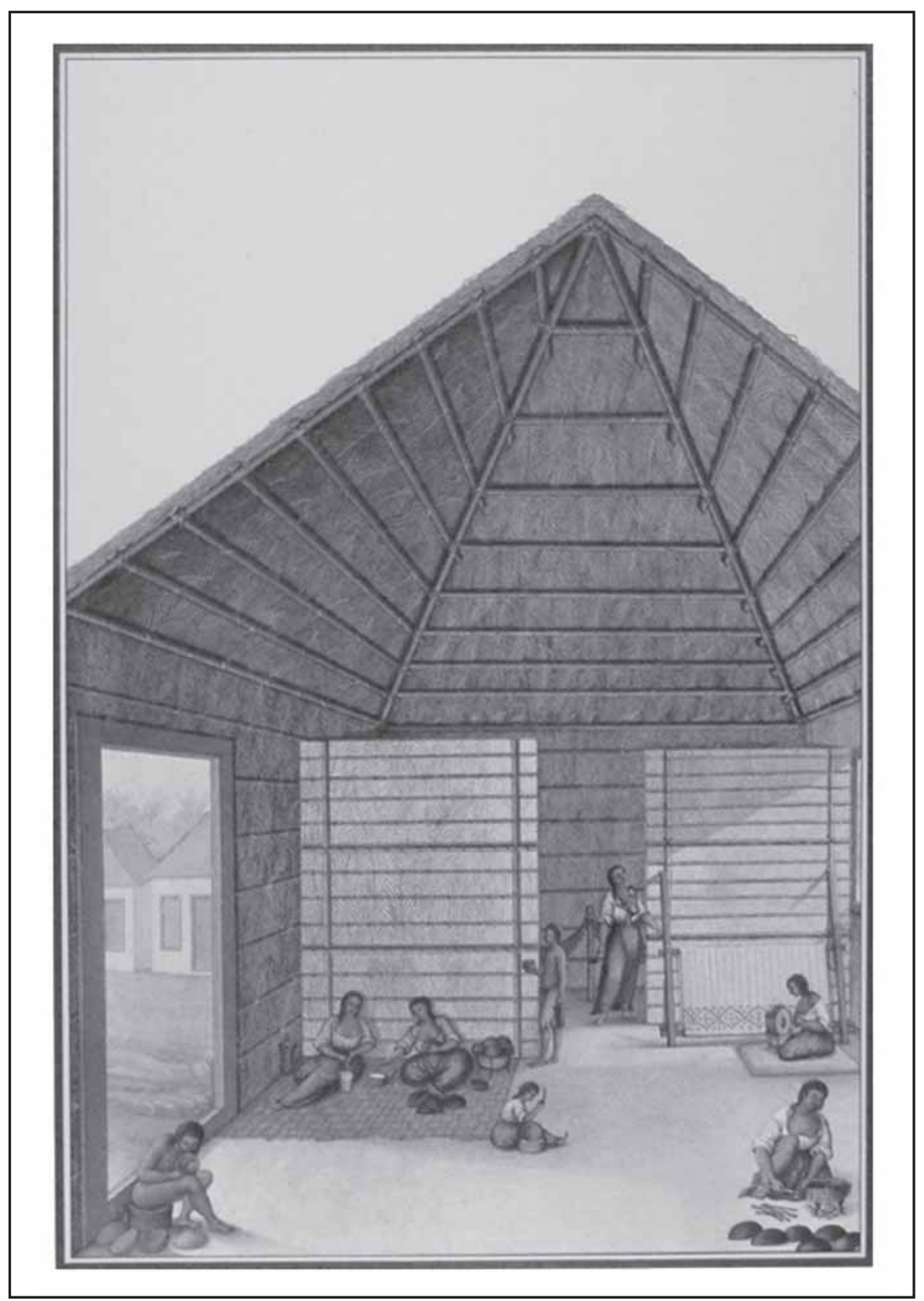

Fuente: Alexandre R. Ferreira, Viagem Filosófica às Capitanias do Grão-Pará, Rio Negro, Mato Grosso e Cuiabá, vol. 1 (São Paulo: Brunner, 1970). 
Figura 2

Una canoa

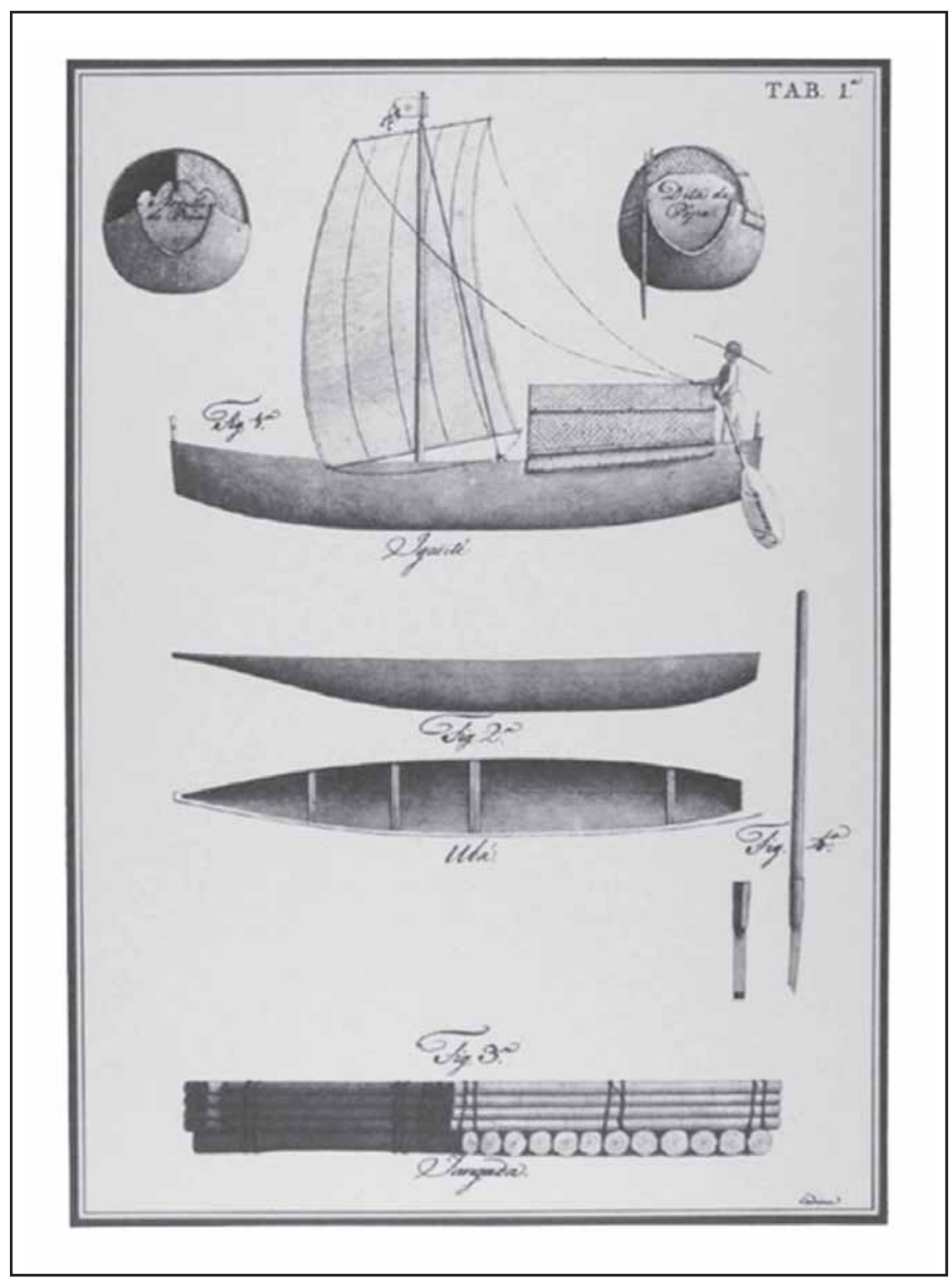

Fuente: Alexandre R. Ferreira, Viagem. 
categoría se incluye la vainilla, la brea, el cacao, la canela, la nuez de Brasil, el clavo de olor, la madera, los aceites vegetales (andiroba, copaíba, cumaru, umeri), piaçaba, puxuri, salsaparrilha y urucú, entre otros ${ }^{9}$.

Comenzando el siglo XVII, la intensificación de la actividad de recolección de las drogas se articuló a dos factores importantes desde el punto de vista metropolitano. Por un lado, las presiones sufridas en el oriente, que llevaron a la corona portuguesa a desarrollar la aclimatación de especies o a buscar sustitutos para las especias orientales en otras partes de sus dominios. Por otro lado, ese mismo interés permitió acelerar el proceso de ocupación de la amazonia, en la medida en que se concedieron exenciones de impuestos, transformando las drogas en una de las razones principales que justificaron el arraigo de los colonos en Grão-Pará. En el XVIII, la intervención promovida por la política pombalina, a través de la compañía monopolista de comercio, acentuaría el carácter oficial de los incentivos que hicieron que las drogas tuvieran un peso aún más significativo en el comercio de exportación ${ }^{10}$.

El camino de la expansión del comercio del cacao permite observar algunos de los elementos de este proceso. Dauril Alden, en su estudio sobre la producción y el comercio de cacao en la amazonia ${ }^{11}$, lo divide en tres momentos diferentes: el que denomina la "era inicial del sistema de librecambio" (1730-1755), el "período del monopolio” de la Compañía de Comercio de Grão-Pará e Maranhão (1756-1777) y, finalmente, la "nueva era del librecambio" (1778-1822).

El primer período fue marcado por los conflictos entre los colonos y los misioneros, feroces competidores en la disputa del comercio del cacao. Los misioneros tenían exenciones de derechos a la exportación y también gozaban de una comodidad relativa, obteniendo la mano de obra necesaria para enfrentar la cosecha de cacao bravío en los interiores. Pero los colonos entraron luego en la disputa por los indios y los créditos para equipar sus propias expediciones de recolección ${ }^{12}$.

9 El perejil fue considerado como eficaz para las enfermedades sexualmente trasmisibles en condiciones medicinales; el clavo, usado en la odontología; el urucú, como colorante y también como remedio para la tos con catarro. Las expresiones cacao bravío (Theobroma sp.) y cacao doméstico (Theobroma cacao) se refieren, respectivamente, al cacao nativo y al cacao cultivado. Se incluye el cacao entre las drogas porque, por lo menos hasta 1784, la mayor parte del producto se originaba en la recolección y no en el cultivo. Alexandre R. Ferreira, Viagem Filosófica ao Rio Negro (Belém: MPEG/CNPq, 1983), 125.

10 Ângela Domingues, “As sociedades e as culturas indígenas face à expansão territorial luso-brasileira na segunda metade do século XVIII”, en Brasil nas vésperas do Mundo Moderno (Lisboa: Comissão Nacional para as Comemorações dos Descobrimentos Portugueses, 1992), 183-207.

11 Dauril Alden, O significado da produção de cacau na região amazônica no fim do período colonial: um ensaio de história econômica comparada (Belém: Núcleo de Altos Estudos Amazônicos - NAEA/ UFPA), 1974.

12 La rivalidad comercial se materializaba en las campañas promovidas por los colonos contra las actuaciones de los misioneros. En 1734, las cámaras de Belém y São Luís reiteraron al rey el punto central del conflicto: el control de los indios por las órdenes religiosas debía limitarse a los asuntos espirituales porque, además de privar de indios a los colonos, los usaban en la cosecha del cacao, extrayendo "más drogas que todos los laicos reunidos”. Ibídem, 35. 
Entre 1730 y 1744, el cacao representó el 90,6\% de las exportaciones registradas en Belém, que entre 1745 y 1753 fueron el 61\% del total. El propio gobernador João da Maia Gama (1724-1728) tenía sus expectativas ligadas a la cantidad de cacao que exportara para el reino, y posiblemente esa relación tan estrecha, unida a las disposiciones reales para incentivar la producción y el comercio del producto, hizo que este -y otros gobernadores- facilitaran la concesión de licencias para las canoas del interior.

Tal competencia solo podía empeorar las condiciones de contratación de los indios de los pueblos. El efecto era inmediato: poblados que se diezman de sus gentes, en un movimiento que se desarrollaba paralelo a una expansión creciente de las tropas de rescate en busca de nuevos brazos para el trabajo. Este es uno de los argumentos que utiliza Alden para explicar la prioridad que se le dio a la recolección del cacao bravío, en detrimento del cacao doméstico en el área amazónica durante el siglo XVIII: las expediciones de recolección eran una extensión de las de rescate, que tenían como principal objetivo la captura de indios ${ }^{13}$.

El período del monopolio empezó con la creación de la Compañía de Comercio de Grão-Pará y Maranhão. Esta debería actuar en dos sectores importantes para permitir el aumento de la producción de cacao doméstico y la exportación global del producto, resolviendo dos problemas cruciales: el del transporte, a través del establecimiento de flotas regulares, y el de la mano de obra, introduciendo esclavos africanos a precios asequibles. Durante el período de actuación de la compañía no se pierde el liderazgo del cacao en la línea de productos exportados, que entre 1756 y 1777 constituyó en promedio el $61 \%$ del total ${ }^{14}$.

La fase que empezó con la extinción de la compañía en 1777 y que se extendió hasta la Independencia de Brasil (1822-1823) se ha llamado la "nueva era del sistema de librecambio”. En ella, el cultivo del cacao se intensificó en otras regiones del país y el nivel de las exportaciones permaneció relativamente estable, incluso hasta mediados de la década de 1780. Desde entonces, a raíz del inicio del conflicto entre Inglaterra y España (1796-1802) y el declive de las exportaciones de cacao de Venezuela, la comercialización del producto amazónico pasó por un período de expansión durante las primeras décadas del siglo XIX. Sin embargo, al final de la década de 1820 los precios comenzaron a bajar ${ }^{15}$.

13 Ibídem, 31.

14 Ibídem, 54. El papel de la compañía en el aumento de la producción y exportación del cacao ha generado evaluaciones opuestas. Manuel N. Dias, en Fomento e Mercantilismo: a Companhia Geral do Grão-Pará e Maranhão (1755-1778), 2 t. (Belém: UFPA, 1970), asegura que la presencia del monopolio aceleró la producción de cacao entre 1755 y 1777, pero Dauril Alden argumenta que, a pesar de ciertas fluctuaciones sustanciales, las cifras fueron similares a las verificadas en la década de 1745-1755, y que por eso no es posible ratificar la posición de Dias, ya que la compañía no contribuyó al crecimiento de la producción de cacao en el área.

15 Alden, O significado, 41. 


\section{Figura 3 \\ Drogas del interior exportadas por la Compañía de Comercio de Grão-Pará}

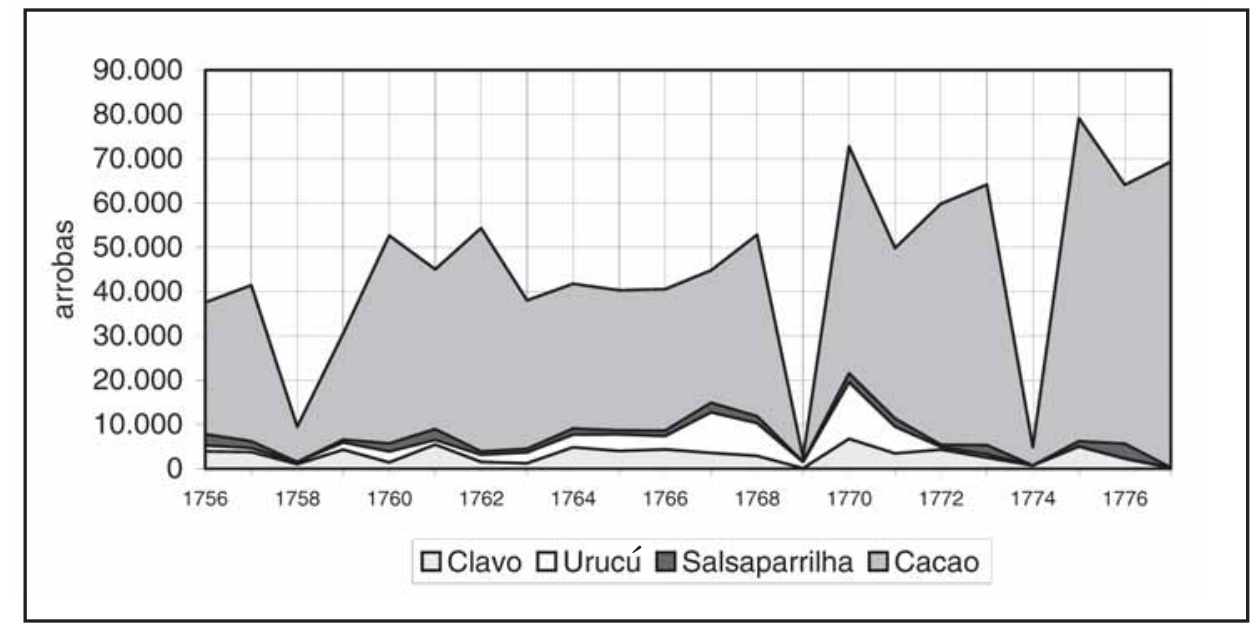

Fuente: Elaborado por la autora a partir de Dias, Fomento, 317-362.

Las zonas de recolección de las drogas eran variadas y se extendieron gradualmente, consolidándose con el establecimiento de poblados que funcionaban como puntos de abastecimiento de víveres e indios. De circulación amplia, las canoas se movieron a través de los ríos Madera, Solimões, Javari y Negro. También se frecuentaron las islas del delta del Amazonas, aunque con una intensidad menor.

Normalmente, el montaje de una canoa comercial seguía los siguientes pasos: los responsables de ella empezaban a preparar la provisión de recursos y los materiales más necesarios a la llegada de las flotas: bretañas, sombreros, telas de algodón, herramientas, licor y otros géneros pequeños. Al terminarse los alimentos, pedían la concesión de la entrada que les autorizaba el viaje y establecían el número de indios necesarios para el abastecimiento ${ }^{16}$.

Si la salida era desde Belém, la época más común era noviembre. En caso de que hubiese interés en establecer factorías para la producción de manteca de tortuga, la salida se adelantaba para el mes de septiembre. Un viaje al interior duraba aproximadamente de seis a ocho meses.

Preparadas las canoas, se partía hacia los poblados a recoger los indios concedidos. Esta era una de las fases más lentas porque, normalmente, era necesario buscar

16 João Daniel, Tesouro Descoberto no Rio Amazonas (Río de Janeiro: Separata dos Anais da Biblioteca Nacional, 1976), 2: 56-63. 
indios en varios lugares hasta alcanzar la cantidad autorizada. Normalmente se trataba de 40 a 50 indios. Buscando reducir el retraso, era común enviar canoas menores a poblados diferentes o también armarlas con esclavos africanos propios mientras se completaban los indios.

Los propietarios de las canoas no acompañaban la expedición. Estas por lo general eran comandadas por unos cabos de canoa, "hombres expeditos y ya experimentados como cabos de sus propias canoas a los que llaman sertanejos y viven algunos años en esta ocupación hasta engrosar sus caudales, hasta que pueden aspirar a otro modo de vida”. El cabo de canoa podía ser blanco, pero el piloto normalmente era un indio o un mestizo denominado jacumaúba.

En los pueblos se presentaban concesiones a los misioneros, y a través del principal $^{17}$ se mandaba llamar a los indios. La preferencia recaía en los mayores de 20 años, aunque los hombres podían ser incluidos en la distribución a partir de los 13 años. Mientras se esperaba la llegada de los trabajadores, se adquirían las provisiones.

Identificados los indios, se procedía al pago. Por el viaje entero, los indios recibían 12 varas de tela gruesa, dos a tres varas de bretaña, pantalones cortos, una gorra o sombrero, una porción de sal, seis agujas y “nada más, antes a veces menos.” Los indios llevaban consigo algunas telas, un sombrero y el resto se lo daban a las mujeres. Llevaban además su remo, el arco, las flechas, una cesta con las camisas, pantalones cortos, hilos y agujas.

A partir de ese momento, la rutina era agotadora. Largas horas de canoa en las cuales iban cambiando la forma de remar según el compás de los de proa:

Aunque son muchos [...] a la señal del compás todos los meten, tiran, y quitan al mismo tiempo del agua como si fuera un solo remo y juntos, al golpe de los remos, van dando rugidos, y haciendo tales griterías que por ellas se sienten estas canoas desde mucha distancia ${ }^{18}$.

En poco tiempo, debido al esfuerzo, los indios quedaban remando desnudos bajo el sol o la lluvia. Si les faltaba la comida usaban el tiquara y para engañar el hambre se apretaban la cintura con un bejuco o acudían a las hojas masticadas de ipadu ${ }^{19}$.

Además de la recolección de drogas (principalmente cacao, perejil y clavo), el trabajo podía incluir el establecimiento de factorías para la producción de manteca de tortuga,

17 Principal es la denominación portuguesa corriente en los siglos XVII y XVIII que identificaba al liderazgo indígena.

18 Daniel, Tesouro, 59.

19 Tiquara es una mezcla de harina de yuca con agua, de vez en cuando sazonada con sal. Ipadu (Erythroxylum coca) es un arbusto cultivado para uso ritual entre los indios del alto río Negro. 
pescado salado, aserrar madera y para preparar los aceites vegetales. Una factoría requería de un establecimiento temporal con la construcción de chozas de paja y la preparación de la tierra para las rozas de subsistencia.

Si la expedición tenía éxito, se preparaban para volver entre los meses de junio y agosto con el fin de aprovechar la llegada de las flotas que debían llevar los productos hacia Europa y lograr de esta manera el reabastecimiento de materiales para las próximas expediciones.

Los cabos recibían la quinta parte de toda la carga de la canoa. Según el relato del jesuita João Daniel, eran los más grandes beneficiados por el viaje, ya que no hacían las inversiones necesarias para equipar las canoas, resultando "ganancia pura y limpia” el pago de su trabajo. Además del quinto, los cabos recurrían a otras estrategias para aumentar sus utilidades: usaban el trabajo de los indios en las horas de descanso o en los días festivos en la recolección de productos para sí mismos; se aprovechaban de las paradas en los poblados o haciendas para vender sus propios productos o incluso preparaban una canoa personal para acompañar la expedición, usando a los indios concedidos, con lo que al final recibían el quinto de toda la expedición y las ganancias de su propia canoa ${ }^{20}$.

Recordando que el jesuita trata del período anterior a la aplicación del Directorio, es importante señalar cuáles fueron las rutinas que se mantuvieron bajo la nueva legislación. El Directorio consideró que el comercio del interior era el más importante y el ramo más útil del comercio del Estado, y les cabía a los directores "usar de la vigilancia más exacta y del cuidado incesante para introducir y aumentar el referido comercio en sus respectivos poblados”. Para lograrlo, debían observar la "vocación” de los poblados por unos u otros géneros, con el objetivo de reducir los costos y diversificar la producción del Estado en su conjunto ${ }^{21}$.

Los indios de los poblados serían persuadidos a comprometerse en los negocios del interior porque, a partir de esta nueva legislación, los resultados de estos negocios se distribuirían proporcionalmente al trabajo de cada uno de los involucrados. Una proporción que pronto se reveló diferenciada: los principales y otros oficiales de la población estarían exentos de ir al interior, teniendo derecho a enviar de dos a seis indios por canoa para recolectar productos en su provecho, dándoles el sueldo establecido por la ley.

Los gastos de abastecimiento de las canoas eran responsabilidad de las Cámaras, en el caso de las villas (Vila), y de los principales, tratándose de pueblos (lugares), reci-

20 Daniel, Tesouro, 65-68.

21 Directorio que se debe observar en las poblaciones de los indios de Pará e Maranhão (1757-1798) (en adelante citado como Directorio), § 46, en Oscar Beozzo, Leis e Regimentos das missões (São Paulo: Loyola, 1983). 
biendo ambos la prerrogativa de enviar de 10 a 12 indios para hacer negocios para su provecho o ventaja ${ }^{22}$.

Considerando los innumerables problemas que se presentaban con los cabos de canoa, su nombramiento debía estar acompañado por los directores para que la elección de las Cámaras o del principal recayera en individuos de "fidelidad conocida, honores y verdad”. Identificados y nombrados, comprometían sus personas y haciendas por lo que recibieran para la canoa y por los daños y perjuicios que su descuido y negligencia pudieran provocar.

$\mathrm{Al}$ regreso de la canoa, los directores hacían una investigación judicial para verificar si los cabos habían cumplido las reglas del negocio, si no distraían los indios en sus servicios particulares, si no los habían tratado con violencia, si no habían negociado los productos de las canoas con los residentes al regresar al pueblo, entre otras irregularidades posibles.

Una vez concluido este rito, hacían un inventario de lo recogido y, con las guías respectivas, el cabo se dirigiría hacia Belém para presentarse ante la Tesorería de Comercio de los Indios que, a su vez, negociaba las mercancías y con lo reunido procedía a efectuar los pagos: los diezmos de la hacienda, los gastos de la expedición, el 20\% del cabo, el 16\% de los directores, el 3\% del tesorero y lo que sobraba, entre los indios involucrados en el negocio.

Una última observación acerca de las "ganancias" de los indios: considerando su "rusticidad e ignorancia”, la remuneración no debería dárseles directamente debido a su incapacidad para administrarla. Recaía en el tesorero la responsabilidad de adquirir las cosas que los indios necesitaran. Como decía el Directorio:

De este modo, acabando de comprender con la evidencia estos miserables indios la fidelidad con que nosotros cuidamos de sus intereses y las utilidades que corresponde a su tráfico, se recuperará la buena fe de que dependen la subsistencia y el aumento del comercio ${ }^{23}$.

Opinión diferente expresó el oidor Antônio José Pestana da Silva con respecto a estas compras hechas a nombre de los indios, estando ya el Directorio en plena aplicación. Aseguraba el oidor que los contratos, que se celebraban presumiendo la libertad de los contratantes, eran un engaño, porque los indios nada escogían y tampoco les compraban los productos que necesitaban. De este modo se presentaban situaciones en que se daba,

22 Ibídem, § 52.

23 Ibídem, $§ 58$. 
[...] una espada pequeña a quien no tiene ni casaca, ni vestidos; algunas medias a quien no trae zapatos y nunca usó de este abrigo; varias cintas que solo por los colores engañan; pedazos de raso a quien en su choza de paja apenas tendrá una soga donde cuelgue y guarde adornos semejantes $[\ldots]^{24}$.

Es necesario recordar que las normas aquí expuestas solo se refieren a las canoas de los poblados y no a las armadas por particulares. No tengo noticia de que se hayan hecho investigaciones judiciales a los cabos privados ni sobre los procedimientos que se seguían con las canoas de los residentes. Con respecto a estas, la documentación apunta hacia la continuidad de los procedimientos que se practicaban durante la administración misionera: persistía la distribución de los indios a través de las "entradas" del gobernador, la concesión del quinto de las canoas a los cabos, los grupos de trabajadores divididos por rango de edad y el valor de los sueldos ${ }^{25}$.

En el caso de las entradas, recaía en los directores recibir el sueldo a nombre de los indios. Del valor depositado, ellos recibían solo un tercio; y el restante era depositado como garantía para los moradores en caso de escape o deserción. Si alguna diferencia había, estaba en la forma de repartir los indios. Durante el régimen de los misioneros, podía distribuirse solo un tercio de los indios de las misiones a los moradores, mientras que el Directorio garantizaba la mitad de los indios. Diferencia, permítasenos decirlo, sustantiva, si además le agregamos el hecho de que los alegados inconvenientes causados por los misioneros estaban definitivamente abolidos ${ }^{26}$.

Todo parecía previsto en el Directorio y el crecimiento del Estado era cuestión de tiempo. Sin embargo, no fue así, para desencanto de los entusiastas de la administración pombalina. Colin MacLachlan ${ }^{27}$ afirma que la mayor disponibilidad de trabajadores indios era simplemente teórica, sobre todo después del aumento de sueldos de 1773. Durante el régimen de las misiones, únicamente la mitad del sueldo se pagaba

24 Biblioteca Nacional de Río de Janeiro, 74, 5, 21. A. J. P. S. Silva, "Meios de dirigir o governo temporal dos Indios", en A. J. Mello Moraes, Corographia Historica, Chronographica, Genealogica, Nobiliaria e Politica do Imperio do Brasil, vol. 4 (Río de Janeiro: Typographia Americana, 1858-1860).

25 Los sueldos se mantuvieron en los valores fijados en 1751 y solo en 1773 fueron aumentados durante la administración de João Pereira Caldas. MacLachlan considera que los bajos sueldos arbitrados y el aumento de la competencia por el trabajo libre presionaron a la administración para aumentarlos. Como ejemplo, recuerda que un piloto podía lograr obtener el doble de los sueldos oficiales si era contratado por particulares. Colin MacLachlan, "Indian Labor Structure in the Portuguese Amazon, 1700-1800”, en Colonial Roots of Modern Brazil, comp. Dauril Alden (Berkeley: University of California Press, 1973), 210.

26 Una de las estrategias usadas por los misioneros era el intercambio de indios entre aldeas de la misma orden. Como la legislación limitaba la retirada de los que hubiesen terminado de recogerse en las poblaciones, los misioneros los removían de un lado para otro, impidiendo el acceso de los colonos a ellos.

27 MacLachlan, "Indian Labor". 
por adelantado, y, mientras estuvo en vigencia el Directorio, el valor total de los sueldos permanecía bajo la custodia de los directores. Este cambio representó una cierta ventaja para los contratantes de indios. Pero, a pesar de tener la garantía de recuperar parte del depósito salarial en caso de fuga de los indios, el aumento de 1773 ayudó a minimizar esta ventaja.

En conjunto, esto representaba una inversión inicial demasiado alta para el montaje de las canoas y los otros servicios, lo que restringió el acceso de la mayoría de los colonos a los indios de los poblados. De esta manera, quienes poseían las fortunas más grandes eran los mayores consumidores del trabajo indio y, al mismo tiempo, solo el acceso a la mano de obra indígena permitía una mayor acumulación de capital. Fundado sobre estas bases, el sistema ayudó a reforzar la concentración de riqueza de las familias establecidas ${ }^{28}$.

La salida para los colonos sin suficiente capital para obtener legalmente indios era evidentemente la ilegalidad. Esto significaba mantenerlos más allá del tiempo en que habían sido concedidos, solicitarlos con la justificación falsa de que serían empleados en el servicio real e incluso aplicar diferentes métodos de persuasión a los directores para obtenerlos al amparo de la legislación.

En 1754, aparece ya la preocupación de las autoridades de Grão-Pará por cohibir las estrategias poco ortodoxas de los residentes para mantener indios en sus propiedades, entre ellas estaban no solo los “acuerdos” con directores titulares -que terminaban relajando los controles al tiempo de las concesiones, facilitando la distribución de trabajadores sin los permisos necesarios-, sino también las llamadas prácticas de “corrupción” y “seducción” que los propios residentes usaban para convencer a los indios para que dejaran sus poblados e incluso abandonar el señor temporal para el cual estuviesen trabajando. En 1764, la corrupción de indios, como la definió la documentación, fue considerada un "crimen abominable” y, como tal, sujeta a los rigores de las multas y la prisión.

La producción de las drogas presentaba además dos problemas recurrentes: el mantenimiento de la calidad de los productos, debido a su adulteración frecuente y también a su recolección indiscriminada, como era el caso del que se cogía todavía verde, no solo para acelerar el montaje de la carga de las canoas, sino también por el hecho de que las semillas verdes eran más pesadas. En la colecta del clavo, el árbol se cortaba completamente para retirarle la cáscara, y el perejil era arrancado hasta las raíces, comprometiendo su reproducción. Alexandre Rodrigues Ferreira (1783) afirmaba que los indios además solían tener la “malicia” de dejar colgadas en los árboles las raíces arrancadas

28 Ibídem, 210-211. 
[...] porque querían que tal perejil se extinguiese de una vez, para ver si así también se extingue la persecución, lo que prueba su pereza y su amor a la ociosidad $^{29}$.

Una buena explicación para ese artificio aparece en João Daniel, que consideró la cosecha del perejil como una de las más difíciles y trabajosas para los indios, porque, siendo género de tierra firme, su recolección implicaba internarse en la selva, donde tenían menor cantidad de alimentos, y para retirarla y alcanzar las raíces debían evitar las espinas. Como se puede apreciar, poco tiempo quedaba para la ociosidad en la colecta del perejil ${ }^{30}$.

\section{Construcción de redes de comercio}

Las actividades de los comerciantes establecidos en Grão-Pará no se limitaban al comercio con la metrópoli. Al contrario, la expansión portuguesa en el valle amazónico penetraba en la intrincada red hidrográfica y alcanzaba los interiores del río Negro, bajando por los ríos Madera y Guaporé, vinculando el Grão-Pará a Mato Grosso en una impresionante red de comercio "monzonero" (monçoeiro) ${ }^{31}$.

Pero, a finales del siglo XVII, el conocimiento del turbulento río de la Madera se limitaba a una misión jesuita establecida en el pueblo de Tupinambaranas. En la primera década del siglo XVIII, la acción de la corona en el área del Madera se dirigía en dos frentes: el incentivo al establecimiento de la misión jesuita y la presencia de tropas de guerra para combatir a los indios que estaban impidiendo el trabajo de la catequesis y la recolección de drogas del interior. En ese período, los jesuitas reportaban en el área un intenso movimiento de colonos de Belém que andaban recogiendo cacao, clavo y cautivos ${ }^{32}$.

29 Llevar frutos verdes de cacao significaba también comprometer la competencia, “dado que entre más rara sea la cosecha de los segundos, tanto mejor se considerará la de los primeros”. Ferreira, Viagem, 126.

30 "Todo el trabajo aborrecido consiste en desviarse de los tallos y sus terribles espinas; y no tienen nada para comer en este trabajo; luego van organizando en manojos estas raíces delgadas y las llevan para la factoría donde las secan, y las atan en manípulos”. Daniel, Tesouro, 62.

31 La importancia de estas redes de circuito interno se discute en Sérgio B. de Holanda, Monções (São Paulo: Brasiliense, 1990), que analizó el sistema de monzones que unía Mato Grosso con São Paulo. Para una lectura más completa con respecto al monzón de Pará, véase: David Davidson, "Rivers \& Empires: the Madeira Route and Incorporation of the Brazilian Far West, 1737-1808" (tesis de doctorado, Yale University, 1970). (En su origen, el monzón es la estación o época apta para la navegación; N. de E.)

32 La misión de Irurises se estableció en 1688, pero en 1691 fue abandonada debido a las enfermedades sucesivas de sus habitantes. Poco después se fundaron las nuevas misiones de Abacaxis y Canumã, localizadas en los ríos del mismo nombre. Luego la primera fue trasladada al margen izquierdo del Madera. En 1712, una nueva se funda entre los ríos Jaruary y la primera cascada del Madera: era la Santo Antônio, llamada después Trocano y, en 1756, Pueblo de Borba. 
Figura 4

Villa de Cametá y plaza de un pueblo con barcos de guerra
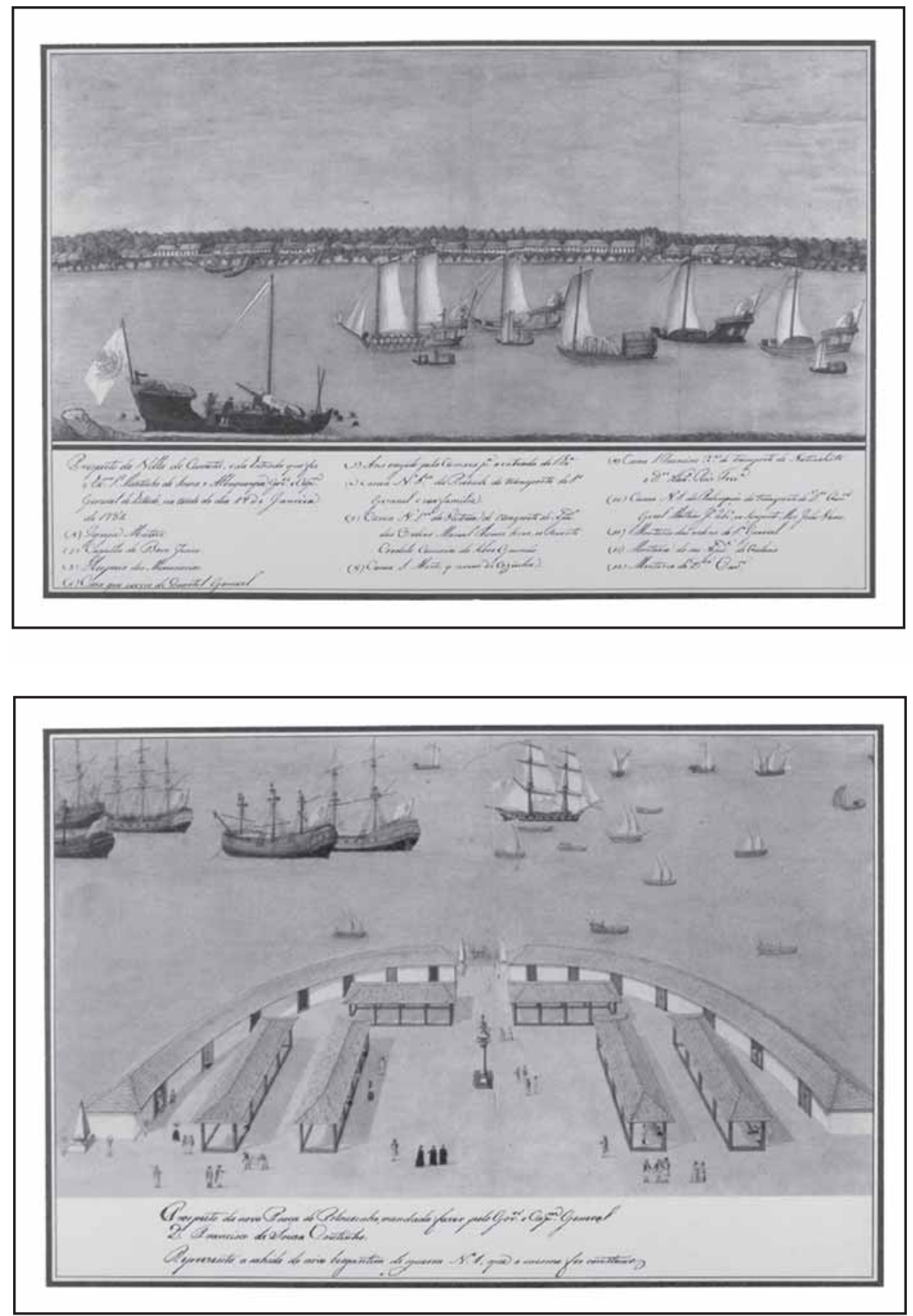

Fuente: Alexandre R. Ferreira, Viagem. 
La segunda parte de la acción de la corona no se hizo esperar mucho tiempo. Los indios torá actuaban intensamente en el área, atacando las canoas que recolectaban clavo y cacao, y contra ellos fue enviada una tropa de guerra que en 1716 prácticamente los extinguió ${ }^{33}$.

Vencidos los torá, se redujo la presión en el río. Seis años después, la expedición de Francisco de Melo Palheta cruzó 23 cascadas del Madera y llegó a la misión española de Santa Cruz de los Cajuabas. No obstante, la navegación por este río se prohibió entre 1733-1737. El desconocimiento de las rutas fluviales y los problemas fronterizos contribuyeron a esta interdicción, así como la preocupación por impedir el despoblamiento de Pará a causa de las minas descubiertas en Mato Grosso en 1734, y para evitar el contrabando de oro y el comercio con los españoles ${ }^{34}$.

En 1752, se permitió la navegación del río Madera, aunque desde 1749 las autoridades coloniales de Mato Grosso venían pidiendo esta autorización. Al abrirse el comercio por el Madera-Guaporé, se prohibió cualquier otra ruta de conexión entre las dos capitanías; interdicción que persistió hasta 1790, cuando se dio permiso a la ruta entre Pará y Goiás, a través de Tocantins, y con Mato Grosso, por los ríos Xingu y Tapajós.

Una vez establecidos los caminos para Mato Grosso, los asuntos que preocuparon a los administradores coloniales tuvieron que ver con el tema de las fronteras con España, sobre todo en el área compleja del Madera-Mamoré-Guaporé, que no estaba definida totalmente en el Tratado de 1750, y también con el asunto del comercio con la zona minera. Con respecto a este último punto, es importante recordar la coexistencia de los sistemas de monzones Tieté-Paraná y Madera-Guaporé: el primero atendía a Cuiabá y a las poblaciones del sur de Mato Grosso; los monzones del norte tenían Vila Bela como centro, atendiendo a los pueblos situados más al oeste de la capitanía.

\section{Monzones del Grão-Pará: “Espaldas a la lluvia, proas a la corriente"}

Las flotas a Mato Grosso no tenían una tarea fácil, si se considera que parte de tramos debía cruzarse remolcándose con cuerdas, en una distancia estimada en

33 João Lúcio Azevedo, Os Jesuítas no Grão-Pará (Coimbra: Imprensa da Universidade, 1930), 269.

34 No hay noticias de que se volviera a intentar la navegación del río Madera hasta el año de 1742 cuando Manuel Félix de Lima, en busca de oro, localiza el Guaporé y después el Madera, llegando hasta Belém. En 1749, José Leme del Prado dejó Mato Grosso y gastó 52 días viajando hasta Belém. En ese mismo año, João de Souza y Azevedo, también en busca de oro, logró hacer el mismo viaje por el Madera. Además de esta, hizo otras exploraciones en São Paulo, Mato Grosso y Pará, principalmente en los ríos Paraguay y Amazonas. Fr. João de São José, "Viagem e Visita do Sertão em o Bispado do Gram-Pará em 1762 e 1763”, Revista do Instituto Histórico e Geográfico Brasileiro (Río de Janeiro), 9 (1847): 81-2 y 92-3; J. R. Amaral Lapa, “Do Comércio em Área de Mineração”, en Economia Colonial (São Paulo: Perspectiva, 1973), 24, y Azevedo, Os Jesuitas, 270. 
770 leguas, acentuada por la corriente opuesta y por la gran cantidad de cascadas para remontar ${ }^{35}$.

Cuando se observa el flujo del comercio de monzones en Mato Grosso, no es difícil notar que solo personas de "gran conocimiento y crédito" habrían podido asumir los riesgos de la empresa. Los obstáculos del camino limitaron el tamaño de las canoas que podían vencerlos a lo sumo con 1.200 arrobas, mientras que las canoas comerciales que se adentraban a los interiores podían llegar incluso a 3.000 arrobas. De este modo se formaban flotas compuestas por embarcaciones que variaban entre $400 \mathrm{y}$ 1.200 arrobas, pudiéndose separar la carga, los suministros y los trabajadores, que representaban, por término medio, un hombre para cada 10 arrobas.

La adquisición de mercancías se hacía en Pará por adelantado; parte de los sótanos de las embarcaciones estaban comprometidos con los materiales necesarios para vencer las cascadas, incluidas las herramientas para las reparaciones. Además, era necesario adquirir esclavos o pedir indios para remar en las canoas, hacerse responsable de los sueldos de los pilotos y prácticos del río y llevar provisiones suficientes, ya que no existían pueblos que pudieran proporcionar alimentos e indios para el reemplazo de eventuales pérdidas.

Esta era la parte más compleja de la jornada, pues en ese punto ya estaba muy reducido el número de indios reclutados para remar, que no solo tenían la costumbre de huir, sino que morían por razón de las fiebres, semejantes a las de "un viaje largo en alta mar y con flujos de sangre" 36 .

El reclutamiento de los trabajadores parecía ser más insuperable que el cruce de las cascadas. En la medida de sus posibilidades, los indios se negaban a realizar el viaje, escapando del reclutamiento en su propia población o huyendo a la mitad del camino. Sin embargo, era posible que esto no sucediera, sobre todo cuando se transformaban en guías y pilotos muy calificados para la jornada ${ }^{37}$.

Recurrir a estos trabajadores ayudaba a reducir los costos, ya que sus sueldos eran menores, permitiendo que un mayor número de personas participara en el convoy. Sin embargo, en la práctica, significaban grandes pérdidas debido a sus escapes repeti-

35 Los barcos eran descargados y empujados desde donde fuera posible: desde las orillas, en las piedras o en medio de las aguas, mientras que las mercancías eran cargadas por tierra. También era posible acomodar la embarcación en madera plana para facilitar su desplazamiento. Algunas cascadas permitían el cruce a remo, pero con las canoas vacías. Ese tipo de cruce obligaba a tener un equipo de trabajadores muy superior al usual.

36 Francisco de Souza Coutinho, “Informação sobre o modo porque se efetua presentemente a Navegação do Pará para Mato Grosso e o que se pode estabelecer para maior vantagem do Comércio e do Estado" (1798), Arquivo Nacional do Rio de Janeiro, Códice 101, vol. 2.

37 Ibídem, § 9. 
dos. La alternativa más segura era el abastecimiento de las canoas con esclavos negros, reduciéndose el número de indios solo al piloto y los expertos en la navegación de las cascadas. Pero esta era alternativa para pocos. El alto precio de los esclavos limitaba la participación en flotas a aquellos que de hecho poseían suficientes caudales como para afrontar esta inversión inicial. De cualquier manera, la elevada inversión terminaba siendo compensada porque los esclavos no escapaban de los convoyes con la misma regularidad de los indios, ya que se contenían "por el miedo del pagano y del país que ignoran”. Además, no puede olvidarse que eran una mercancía más (y muy valiosa) en el mercado de Mato Grosso ${ }^{38}$.

Con tantas dificultades, resulta imposible dejar de notar que una ruta tan compleja solo podía ser igualmente rentable, y que ciertamente los precios de las mercancías negociadas en Mato Grosso compensaban las enormes inversiones de capital de los comerciantes de Pará.

Un viaje completo de los monzones podía extenderse por más de un año, y solamente la navegación consumía entre seis y siete meses. Solo para pasar las cascadas se gastaban de tres a cuatro meses. En el viaje de subida, la carga estaba compuesta por las manufacturas importadas, sobre todo durante el período de actividad de la Compañía General de Comercio: tejido, bienes domésticos, herramientas e instrumentos de trabajo, adornos, armas, municiones y otros abastecimientos como azufre, pólvora y metales. Fuera de esto, se incluían bienes fabricados localmente como los productos alimenticios regionales, drogas del interior y bienes manufacturados. Los esclavos también eran parte del cargamento. Al regreso de las monzones, este era menos variado, y predominó el transporte de oro y diamantes de las minas. También se llevaban cereales, azúcar, tejidos gruesos, drogas de Mato Grosso y sal.

Vencer las cascadas era la primera necesidad de los convoyes del río Madera. Así, varias propuestas surgieron para reducir la dificultad, entre ellas la rectificación y la apertura de canales de navegación para rodearlas; propuesta que se mostró difícil de ser realizada debido a la gran variación de las corrientes en función de las inundaciones de los ríos.

Otra queja reiterada en la ruta de Mato Grosso, durante el siglo XVIII, era la inexistencia de poblaciones precisamente en su tramo más difícil. Se propuso que se estableciera por lo menos un pueblo a la altura de la primera cascada para ayudar a las necesidades de las flotas. Otra propuesta, defendida por el gobernador Souza Coutinho,

38 A finales del siglo XVIII, el precio de un esclavo estaba entre $130 \$ 000$ y $150 \$ 000$ réis, mientras que el jornal de un carpintero o calafate indio reclutado en las poblaciones variaba entre 120 y 80 réis, respectivamente. Además, mientras funcionó la Compañía General de Comercio, existía el recurso del adelanto en los alimentos y esclavos para la formación de los convoyes, con créditos que se pagaban al retornar de Vila Bela a Pará. 
se hizo a finales del siglo XVIII y consistía en el establecimiento no de uno, sino de una serie de establecimientos que hicieran posible la formación de una verdadera red de comercio en el área con la presencia de comerciantes de las dos capitanías, responsables de la adquisición y el envío a los destinos respectivos. Pero él mismo reconoció que la propuesta, aunque adecuada para el desarrollo del comercio, era de muy difícil ejecución ${ }^{39}$.

Con los ajustes necesarios, la propuesta de Coutinho se convirtió en ley (12-05-1798) y se estableció un plan conjunto de intervención de las administraciones de las dos capitanías. En Pará, dos canoas de 2.000 arrobas deberían estar listas a llevar las cargas hasta la nueva población cada seis meses. De Mato Grosso sería destacado un cuerpo de 60 a 80 soldados para apostarlos en las cascadas, y empleando canoas iguales efectuar el transporte de las cargas en los trechos con más cascadas y llevar las mercancías hasta Vila Bela ${ }^{40}$.

La ubicación de una nueva población en la cascada de San Antonio marcaba el fin de las responsabilidades de Pará y el inicio de las de Mato Grosso, pero no debía ser simplemente un pueblo más de indios. En este lugar, Coutinho procuraría ensayar sus ideas acerca de los cuidados que debían rodear la fundación de una población duradera, para que esta no decayera por el descuido de los directores titulares e "infidelidades" de los indios recién congregados, como había sucedido con otras de la capitanía del Río Negro. La nueva población de Crato era, a su manera, un pueblo-laboratorio ${ }^{41}$.

Para atender las necesidades de los convoyes era necesario contar con personal especializado destinado exclusivamente a este fin. Así se propuso la formación de un cuerpo con gente de Mato Grosso, más habituada al mal tiempo local y con indios debidamente "aclimatados". Para proporcionar el sustento, entraban en escena los nuevos habitantes de Crato: hombres blancos y esclavos:

[...] los únicos labradores que se consiguen en estos países, y con estos es que se debe fundar y con estos es que se puede contar en las ventajas de una población.

Los indios también podrían ser parte de este nuevo perfil de pobladores, pero solamente los que se unieran libremente, en especial aquellos que ya estuvieran viviendo en las poblaciones, y no los recién salidos de la selva. Pero la ley hacía énfasis en que

39 Coutinho, “Informação", § 15.

40 Ibídem, § 18.

41 En el siglo XVIII, las 17 cascadas del Madera-Guaporé eran conocidas por las siguientes denominaciones en la dirección Pará - Mato Grosso: 1. S. Antônio, 2. Salto, 3. Morrinhos, 4. Caldeirão, 5. Jirau, 6. Três Irmãos, 7. Paredão, 8. Pederneira, 9. Araras, 10. Ribeirão, 11. Misericordia, 12. Madeira, 13. Lajes, 14. Pau-grande, 15. Bananeira, 16. Guajará Açu y 17. Guajará Mirim. 
los esclavos debían preferirse en el trabajo en lugar de los indios, y para eso la importación de negros desde Angola, Benguela y otras capitanías del Brasil debía ser estimulada y facilitada ${ }^{42}$.

El nuevo establecimiento avanzaría muy despacio y acabó teniendo un destino diferente del que se proyectó para un pueblo-modelo: los colonos eran gitanos, desterrados y "malhechores", poco habituados a la agricultura:

[...] (estaban) sin el pan, sin el sustento y sin vestir, muriendo muchos en el desamparo, y el resto se dispersó por la provincia entera.

La experiencia de Coutinho terminó convirtiéndolo en un destino de destierro político. En 1828, apenas quedaba un pequeño destacamento que al retirarse prendió fuego al cuartel y presidio de la población ${ }^{43}$.

A finales del siglo XVIII ya existan señales de que la importancia y la frecuencia de la ruta a Mato Grosso estaba disminuyendo: el fin de la compañía y de sus préstamos, los altos impuestos a las mercancías que se imponían en Pará y el crecimiento del comercio en los puertos del sur señalaban un progresivo cambio de dirección. Finalmente, la instalación de la corte en Río de Janeiro marca la consolidación de esta tendencia, ya que buena parte de los comerciantes se desvió hacia la nueva ruta, llevándose además sus capitales y su crédito de Pará ${ }^{44}$.

\section{Negociar y endeudarse: la Compañía General de Comercio}

Al comienzo del siglo XIX, los naturalistas Spix y Martius registraron en la plaza Belém de Pará una variación estacional del comercio, estrechamente ligada a la llegada de las canoas de los interiores cargadas con los múltiples géneros del comercio regional. Solamente con el arrivo de estas embarcaciones se veía alguna animación en las calles de la ciudad, cuando se asistía a los movimientos de los cargadores indios que transportaban las cosas hasta las aduanas y los numerosos almacenes. Fuera de estos momentos, era una plaza muerta.

42 Los residentes, a través de una financiación de cinco años, recibirían esclavos, géneros, herramientas e instrumentos necesarios para formar sus propios establecimientos.

43 Lourenço Araújo Amazonas, Dicionário Topográfico, Histórico, Descritivo da Comarca do Alto Amazonas (Manaus: Associação Comercial do Amazonas/Fundo Editorial, 1982), 59. La historia del pueblo no termina en el incendio. En 1859 el lugar de Crato se convirtió en feligresía, fue transferida a la población de Baetas al año siguiente. En 1868, se transfirió nuevamente a la población de Manicoré, elevada a la categoría de villa en 1877. Las gentes establecidas inicialmente en Crato (en particular los gitanos) huyeron hacia lugares menos insalubres, y todavía hoy se observan restos de la presencia gitana en las fiestas populares de Manicoré (Amazonas).

44 Coutinho, “Informação", § 12. 
Esa dependencia en que el comercio de Pará está de la producción del interior no brinda una opinión muy favorable del espíritu de iniciativa de los comerciantes de aquí ${ }^{45}$.

En un intento por establecer las razones para ese tímido "espíritu de iniciativa”, los naturalistas destacan "el genio callado del paraense que está satisfecho con la menor ganancia” y la inexistencia de grandes capitales en el comercio local. Dejando a un lado la evaluación dudosa en cuanto al genio poco especulativo de los paraenses, podemos concentrarnos en la segunda parte del argumento, en la medida en que no sería la primera y ni la última vez que se recurriría a la fórmula de la "inexistencia de capitales” para explicar la debilidad relativa del comercio de Pará.

En la segunda mitad del siglo XVIII esa misma debilidad aparece con colores más fuertes entre las principales preocupaciones del gobernador Francisco Xavier de Mendonça Furtado.

Yo vine a una tierra donde no solo el comercio es desconocido, sino que nunca oyeron estas personas hablar mínimamente de ello; viniendo los comisarios de Lisboa a robar a estos moradores, ellos se desquitan no pagándolos, o haciéndolo con géneros falsos y por precios exorbitantes, y como estos establecimientos no es mucho lo que tienen, llegan al punto de que es casi imposible reestablecerlos ${ }^{46}$.

En rigor, la actuación de los comisarios no fue la principal causa de las limitaciones de la plaza de Belém. De una manera más general, en la evaluación de Furtado, la ruina del estado se hallaba estrechamente ligada a la "perniciosa” acción de los misioneros que, adueñándose de los indios, llevaron el comercio a la decadencia, monopolizando a los trabajadores necesarios para la extracción de productos del interior, restringiendo el acceso de los particulares a esos trabajadores, concentrándose en la producción de alimentos y debilitando la hacienda real con sus exenciones de impuestos. Fueron también los misioneros los que generaron un cierto grado de autonomía de la producción local, limitando el desarrollo mercantili ${ }^{47}$.

La solución pombalina para contener las acciones de los misioneros, liberar a los indios y desarrollar el comercio pasaría también por la aplicación del monopolio mercantil. La instalación de la Compañía General de Comercio de Grão-Pará y Maranhão

45 Johann B. von Spix y Karl F. P. von Martius, Viagem pelo Brasil (1817-1820) (Belo Horizonte: Itatiaia; São Paulo: Edusp, 1981), 32-33.

46 Marcos Mendoça, Amazônia na Era Pombalina: correspondência inédita do governador e capitãogeneral do Estado do Grão-Pará e Maranhão, Francisco Xavier de Mendonça Furtado, 1751-1759 (Río de Janeiro: IHGB, 1963), 1: 44.

47 Ibídem, 3: 1.157. 
se realizó en 1755 . No se trataba de una experiencia aislada en la política ilustrada portuguesa e incluso no era la primera vez que el Estado portugués intentaba acompañar las tendencias a la aplicación de un sistema de monopolio en el comercio colonial de Grão-Pará, ya que en 1682 se había creado la Compañía de Comercio de Maranhão, con resultados desastrosos que culminaron en la Revuelta de Beckman en 1684-1685, entre los colonos de Maranhão ${ }^{48}$.

Después de esta tumultuosa experiencia, solo en la segunda mitad del siglo XVIII comenzó a esbozarse una nueva compañía de comercio con capital colonial. La intervención del gobernador Mendonça Furtado fue esencial en la articulación de la empresa. Convencido de que la forma de desarrollar el comercio paraense pasaba por la organización de una compañía de comercio, buscó el apoyo de las personas principales de la tierra. Pero los "hombres de negocios" convocados por Furtado, aunque reconocieron la utilidad de la propuesta, en la práctica la rechazaron pues se negaron a participar en la compañía argumentando "frívolos pretextos", como contaba con desaliento a su hermano. Con el apoyo de los militares, Furtado continuó intentando formar la compañía y consiguió finalmente recaudar un modesto capital de 32.000 cruzados $^{49}$.

La negativa inicial de los principales "hombres de negocios” de Grão-Pará a participar en la compañía propuesta por Furtado resulta sintomática. Desgraciadamente, no menciona cuáles fueron los "frívolos pretextos" que los comerciantes presentaron, pero su correspondencia hace pensar en algo más que eso. Al intentar identificar los cuadros administrativos de la nueva compañía, Furtado sondeó a un importante comerciante irlandés establecido en Maranhão, Lourenço Belfort ${ }^{50}$.

La reacción inicial fue negativa: no quiso participar en la empresa en el momento inicial y después (quizá por esa misma razón) no volvió a ser considerado para su

48 Además de la Compañía de Grão-Pará, fueron creadas la Compañía de Pesca de la Ballena en las costas de Brasil (1755); la de Pernambuco y Paraíba (1759); la de los Vinos del Alto Douro (1765) y la de las Pesquerías de Algarve (1773).

49 “Carta de Francisco Xavier de Mendonça Furtado a Sebastião José de Carvalho y Mello” (Pará, 24. 01.1754), Biblioteca Nacional de Río de Janeiro.

50 Francisco J. Santos, Além da conquista: guerras e rebeliões indígenas na Amazônia pombalina (Manaus: Universidade do Amazonas, 1999), 238. En su trayectoria por la región, Lourenço había frecuentado ya muchas paradas hasta establecerse como comerciante y propietario en el Maranhão, además de haber participado en las tropas de rescate en el río Branco, trayendo prisioneros para abastecer sus propiedades en 1740. La figura de Lourenço Belfort todavía puede sorprender. Con poco margen de error se trataba de Lancelot de Belfort (Dublín, 1708 - S. Luís, 1775). La familia Belfort tenía origen noble, por ser descendiente de Robert, el Misericordioso, Rey de Francia; de Alfonso VI, Rey de León y Castilla, y de Guillermo, duque de Normandía, después Rey de Inglaterra. Se registra la presencia de un último irlandés Conde y Príncipe de Belfort en Maranhão, donde ejerció varios cargos públicos entre 1742 y 1759. En 1758 Lancelot de Belfort recibió el Hábito de la Orden de Cristo de Don José I y en 1761 fue armado caballero de la misma orden. Dejó testamento en S. Luís fechado el 15 de marzo de 1775. 
administración. Después de establecerse la compañía, cambió de actitud y pidió su entrada adquiriendo cinco acciones. Furtado pareció finalmente descubrir las razones de su "rechazo" inicial: de acuerdo con la información obtenida, los proyectos de Belfort eran mucho más audaces que tener algunas acciones. Había pensado en establecer un negocio propio para abastecer de carnes saladas a los almacenes y dedicarse al tráfico de los esclavos con otro comerciante de Maranhão. Definitivamente no parece ser la actitud de un hombre de pocos caudales ${ }^{51}$.

Es más que evidente que la plaza paraense no era la más generosa en términos de recursos, como ya lo señalaron suficientemente otros autores importantes. Uno de los indicadores más usados es la introducción tardía de la moneda, entre 1749-1750, y el mantenimiento de productos como cacao y algodón, que funcionaron como dinero en el lugar por un largo período. Sin embargo, por lo que se nota entre líneas en las pretensiones de Belfort, en el lugar podría conseguir muchos más recursos que los 32.000 cruzados que Furtado reunió con sus esfuerzos. Es muy probable que los hombres de negocios de Pará estuvieran aún más vinculados a los comisarios volantes y sus "grandes extorsiones" de lo que la experiencia de Furtado podía percibir en los momentos iniciales de su administración.

Evidentemente, los fondos reunidos eran insuficientes para dar inicio a la empresa al entrar en escena la Compañía General de Comercio con una fuerte intervención de la administración metropolitana. Los objetivos de la compañía eran ambiciosos: establecer conexiones regulares entre Belém y S. Luís con la metrópoli a través de un sistema de flotas y abastecer el mercado local con esclavos de Angola, Benguela, Guinea e incluso de Mato Grosso ${ }^{52}$.

La compañía creada por Pombal se distanciaba mucho de la propuesta inicial que realizó Furtado. Se pidieron para la nueva compañía tres privilegios reales: la exención de los derechos de la madera cargada en el viaje de retorno de las naves que trajeran los esclavos de África, la protección al capital de los accionistas contra la ejecución de deudas contraídas a posteriori y contra su confiscación, inclusive en los casos de lesa majestad. La nueva compañía, además de estos derechos, tendrá muchos otros.

51 “Carta de Francisco X. M. Furtado a Pombal” (Mariuá, 14.10.1756), en Mendoça, Amazônia, 3: 994995.

52 La compañía nació bajo la señal de la protesta. En Lisboa, la de la Mesa del Bien Común, silenciada por el Marqués de Pombal con su disolución. En la colonia no se registraron inicialmente señales de rechazo, exceptuando a los religiosos. Esta oposición, identificada en Lisboa y en la colonia, en parte pudo deberse a la misma campaña adelantada por el gabinete pombalino contra las órdenes religiosas, con particular atención a la Compañía de Jesús. De hecho hay autores que creen que fue la oposición de los misioneros a la compañía de comercio la que incrementó la virulencia de la persecución de Pombal contra estos religiosos, culminando con su expulsión en 1759. Charles Boxer, O Império Colonial Português, 1415 - 1825 (Lisboa: Edições 70, 1981), 183-184, y João Lúcio Azevedo, Estudos de História Paraense (Belém: Secult, 1994), 20-70. 
Con la entrada de los comerciantes de Lisboa se constituyó una empresa de amplios poderes que disfrutaba de muchos privilegios, que se irían ampliando progresivamente. A la compañía se le aseguró la exclusividad del comercio del estado de Grão-Pará y Maranhão con ganancias fijadas entre el 15\% (las "haciendas mojadas") y el 50\% (las "haciendas secas"); la importación de los esclavos africanos; el comercio de las islas de Cabo Verde y de la costa de Guinea durante veinte años, cargando a la compañía, en compensación, con el pago de las nóminas reales (seglares y eclesiásticas) y con el fortalecimiento de la defensa militar para una mayor seguridad de su comercio ${ }^{53}$.

En cuanto al transporte y comercialización de las mercancías de los particulares, al principio estos podrían depositar sus productos en la compañía o entregarlos a sus representantes en Lisboa, aunque el transporte se llevaba a cabo en la flota de la empresa. Esta posibilidad de escolta fue revocada en 1760, a pedido de la junta del consejo administrativo, alegando fraude por parte de los particulares, y a partir de entonces la compañía solo estuvo autorizada para recibir los bienes en consignación.

En 1761, los esclavos introducidos por ella en los puertos de Belém y S. Luís fueron exentos del pago de derechos a la hacienda real así como de los emolumentos de los oficiales de las respectivas aduanas. Entre 1764-1771, fue exenta del pago de la entrada y salida del añil y del jengibre exportado de Pará y Maranhão, agregándose a la exención que ya disfrutaba con relación al café. Su oro estaba libre de impuestos, se le quitaron los "medios derechos" de todos los productos que transportara de GrãoPará y Maranhão a Lisboa y, de la misma forma, de toda clase de artículos destinados al consumo de la compañía. Además, en 1766, una nueva legislación determinaría que los títulos de la compañía tendrían en el comercio el valor del dinero líquido.

En 1770, la compañía recibió el 25\% del valor de los cargamentos que salieran de Pará hacia las fronteras hispanoportuguesas, el 10\% de los derechos de la salida en esta misma ruta, a título de fondo para responder por una parte o toda la hoja de pagos de la oficina de ese proveedor, y el 32\% para el mantenimiento de las fortalezas y las tropas. Sin contar el 8\% destinado a ganar "la buena voluntad" de los gobernantes castellanos para el fomento de esta nueva ruta comercial ${ }^{54}$.

La administración local era ejercida por dos representantes de la compañía establecidos en Belém, en S. Luís, en Cacheu, en Bissau y en Cabo Verde, y unos comisarios radicados en las principales plazas europeas (Génova, Cádiz, Marsella, Bristol, Londres, Amberes, Ruan, Hamburgo y Amsterdam). En la ruta de Belém llegaron a operar 33 barcos y en la de S. Luís, 52. Las flotas cubrieron la ruta África-S. Luís-Belém-

53 Esas consideraciones se basan principalmente en Dias, Fomento, 240-241. En cuanto a la cantidad de acciones, el mismo autor asegura que el número nunca se completó, ya que en los balances de la compañía aparecen solo 1.164 acciones.

54 Ibídem, 218. 
Lisboa realizando el transporte de esclavos, recibiendo las mercancías coloniales y embarcándolas para Lisboa y Porto, donde eran comercializadas con las otras plazas europeas con una regularidad, por norma general, de una flota cada año ${ }^{55}$.

Las mercancías introducidas por la compañía se componían de productos alimenticios de origen portugués y las manufacturas inglesas o de las fábricas metropolitanas (herramientas, tejidos, platos, sombreros). La venta a plazo de tejidos y esclavos en Belém y S. Luís hacía parte importante de los negocios locales de la compañía, que aplicaba plazos para el pago que variaron de seis meses a un año para la liquidación de la deuda, cobrando intereses del 5\% anual en caso de dilación del período establecido.

Debido a tantas prerrogativas, sería necesario cuestionar los desdoblamientos de una creación de esta envergadura frente a las diferentes alianzas políticas que Portugal tenía con otras naciones europeas, particularmente con Inglaterra. En realidad, aunque estaba rodeada de la protección real, la compañía actuaba en las fronteras de los principales canales de comercio y no conseguía hacerle sombra al equilibrio del comercio anglo-portugués. Como aseguró K. Maxwell ${ }^{56}$, es cierto que la creación de la compañía sirvió indirectamente para debilitar los intereses de las casas inglesas establecidas en Portugal, porque la campaña antijesuita que la acompañó acabó por limitar la acción protectora del gobierno británico, que estaba lejos de asumir el papel de aliado de la orden. Sin embargo, en términos más objetivos:

La compañía y la abolición de los comisarios volantes no eran, en la superficie, de manera alguna perjudiciales a las casas británicas involucradas en el suministro de bienes para el tráfico regular de las flotas, y solo un ataque a sus intereses justificaría una acción por parte de Londres ${ }^{57}$.

Un balance completo de los resultados prácticos de la actuación de la compañía en Grão-Pará está, como ya se dijo, minado por posiciones opuestas. Sin embargo, y a pesar de no existir un juicio equilibrado, es necesario precisar antes bajo qué punto de vista se está procesando el análisis. Si se considera la posición de la corona portuguesa, la compañía hizo posible un cierto traslado de responsabilidades y la liberación de ciertas obligaciones de mantenimiento que originalmente eran responsabilidad de la hacienda real, incluyendo el pago de las nóminas, el mantenimiento de las fortalezas y el traspaso de recursos para la colonia ${ }^{58}$.

55 Analizando la composición de los embarques, Carreira afirma que de las 64 naves solo 19 no estaban involucradas en el tráfico de esclavos y dos más eran naves de guerra, por lo tanto, de protección a los convoyes, lo que quiere decir que se destinarón el 67\% de las naves al tráfico de almas. Antônio Carreira, As Companhias Pombalinas de Navegação, Comércio e Tráfico de Escravos entre a Costa Africana e o Nordeste Brasileiro (Lisboa, 1969), 50-51.

56 Kenneth Maxwell, Marquês de Pombal: paradoxo do Iluminismo (Río de Janeiro: Paz \& Terra, 1996).

57 Ibídem, 66.

58 De acuerdo con Nunes Dias, solo en los años de 1760, 1769, 1773-1776 y 1778 Belém recibió moneda enviada de Lisboa a través de la hacienda real. "La compañía, sin embargo, nunca dejó de recibir letras de la Tesorería”. Dias, Fomento, 66-67. 
En el caso de la colonia, la misma presencia de comerciantes locales entre los accionistas ya indica resultados, si no extraordinarios, por lo menos adecuados para atender a sus necesidades. Si se consideran simplemente las inversiones en el cultivo y mejora del arroz, ya es posible notar algunos resultados interesantes ${ }^{59}$.

Las órdenes religiosas en general, y la de los jesuitas en particular, perdieron bastante espacio con la implantación del monopolio, de la misma manera (pero no por las mismas razones), los comisarios volantes. Nunes Dias también menciona a los comerciantes de las haciendas y a los comerciantes pequeños establecidos en la colonia. Estos últimos, involucrados en el crecimiento de las deudas provocadas por los adelantos para la adquisición de mercancías y esclavos, se vieron ante la necesidad de dar sus productos agrícolas y de recolección del interior a los precios fijados por la compañía. Aunque se considere el fin de la prerrogativa de los moradores de enviar sus productos en otros barcos (1760), es innegable el crecimiento vertiginoso del volumen exportado, lo que indica, de una manera rápida, que la compañía era capaz de hacer valer sus derechos de monopolio y también su penetración en los mecanismos de crédito de los residentes en la colonia. En cifras globales, las exportaciones de los particulares representan el 20\% del total exportado por ella durante todo su período de actuación.

\section{Figura 5 \\ Valor de los bienes exportados por la Compañía de Comercio} (cuadro comparativo)

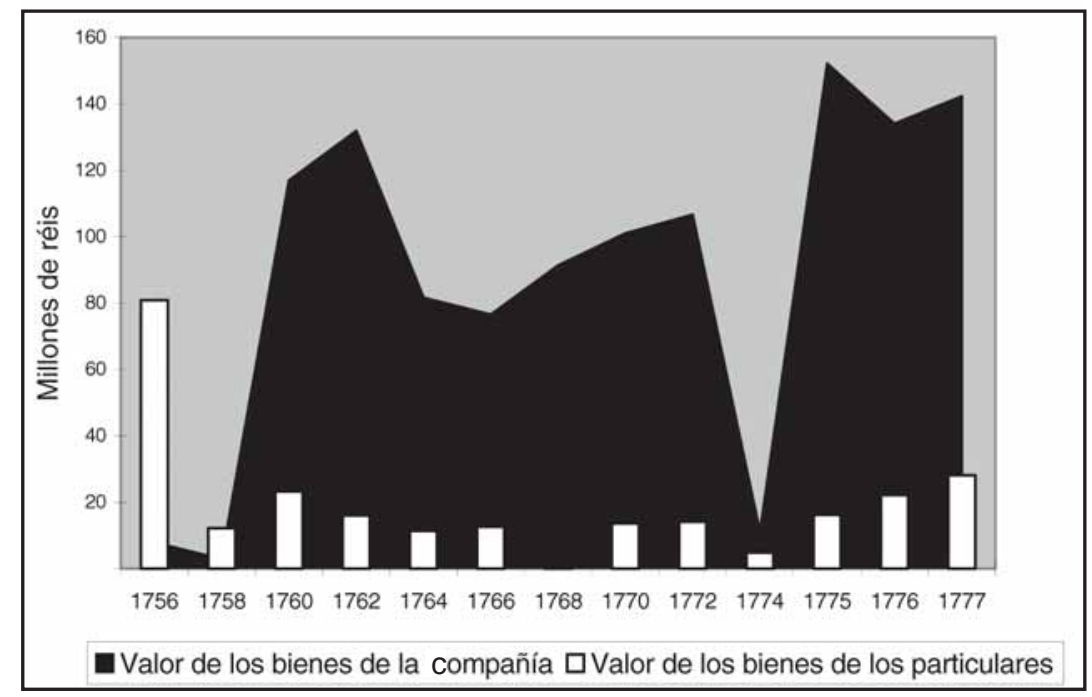

59 Una vez más, Lourenço Belfort ayuda a entender ciertos desdoblamientos. Usando parte de los incentivos de la compañía, sus propiedades alcanzaron una marca de 10.500 alqueires de arroz en 1770, siendo toda la producción adquirida por la compañía. A partir de 1771-1772, con el crecimiento de la producción de arroz, empieza a invertir en la construcción de molinos de piedra, para sustituir a los de madera, empleados en Maranhão. Belfort vuelve a aparecer en la delantera, firmando con la compañía un contrato de suministro de 250 arrobas de arroz por año. Ibídem, 1: 438, 442-443. 
Las críticas y quejas con respecto a las acciones de la compañía solo se harían explícitas con la caída de Pombal. Pero desde antes se registran protestas en Grão-Pará, una de ellas la del obispo João de S. José. Su consideración principal se refiere a los altos precios cobrados por los capitales introducidos en el estado y a los altos intereses, que el obispo no duda en calificar como usura ${ }^{60}$.

Otras quejas se referían a la poca cantidad de bienes y de esclavos que llegaban a Belém. En cuanto a estos últimos, una observación constante entre los residentes de Pará era que las mejores “piezas” se quedaban en Maranhão y los que llegaban a Pará lo hacían débiles y enfermos. Manuel Bernardo de Melo y Castro, sucesor de Furtado en la administración del estado, anotó un conjunto de problemas creado por las malas administraciones y el mal funcionamiento de la compañía. Uno de ellos era la constante animosidad y tensión entre los trabajadores provocada por la frecuente falta de bienes, sobre todo los de uso de la tierra.

Al entregar los productos del interior en la Tesorería de Comercio, los indios debían recibir a cambio su parte del pago para la adquisición de las cosas que necesitaran. Sin embargo, como los almacenes de la compañía estaban "limpios sin cosa alguna”, dejaban sus pagos depositados en la Tesorería y los obligaban a contentarse con algunas pocas varas de algodón. Si esta carencia persistía, aseguraba Melo y Castro, aumentarían las dificultades para contratar indios en las canoas del interior.

Y van uniformemente todos diciendo que las drogas que extraen no son suyas, como nosotros queremos persuadirlos, sino que son todas para los blancos, que los engañan con dos varas de algodón espeso, lo que no les pasaba en los tiempos de los sacerdotes, porque ellos les hacían pagos más abultados [... $]^{61}$.

La importancia de Grão-Pará en la contabilidad de la compañía puede verse en el momento de la liquidación de la compañía cuando los stocks son identificados y estimados por el comité. En Grão-Pará se concentró la mayor parte del valor de sus mercancías. Por los análisis disponibles se verifica que la creación de esta empresa monopolista fue capaz de atender una serie de necesidades y superar ciertas limitaciones importantes que la administración colonial era incapaz de asumir. Desde el punto de vista del incremento de la producción y el comercio locales, es necesario un poco más de polvo de los archivos para definir las relaciones entre comerciantes y

60 Además del “interés común”, el obispo tenía razones personales para quejarse de los administradores de la compañía: su cargamento de té de Lisboa había sido considerado demasiado grande para constituir simplemente el consumo doméstico y fue reducido drásticamente a un volumen que se consideró más aceptable. Estaba enfadado con esa intervención de la junta administradora en su casa y en "los negocios de Jesucristo”. São José, “Viagem”, 73-75.

61 La correspondencia de Manuel Bernardo de Melo y Castro a Sebastião José de Carvalho y Melo (Pará, 5. 08. 1759), citado en Arthur Reis, Aspectos da Experiência Portuguesa na Amazônia (Manaus: Governo do Estado, 1966), 146. 
Figura 6

Ingenio en Pará y rueda hidráulica en un ingenio
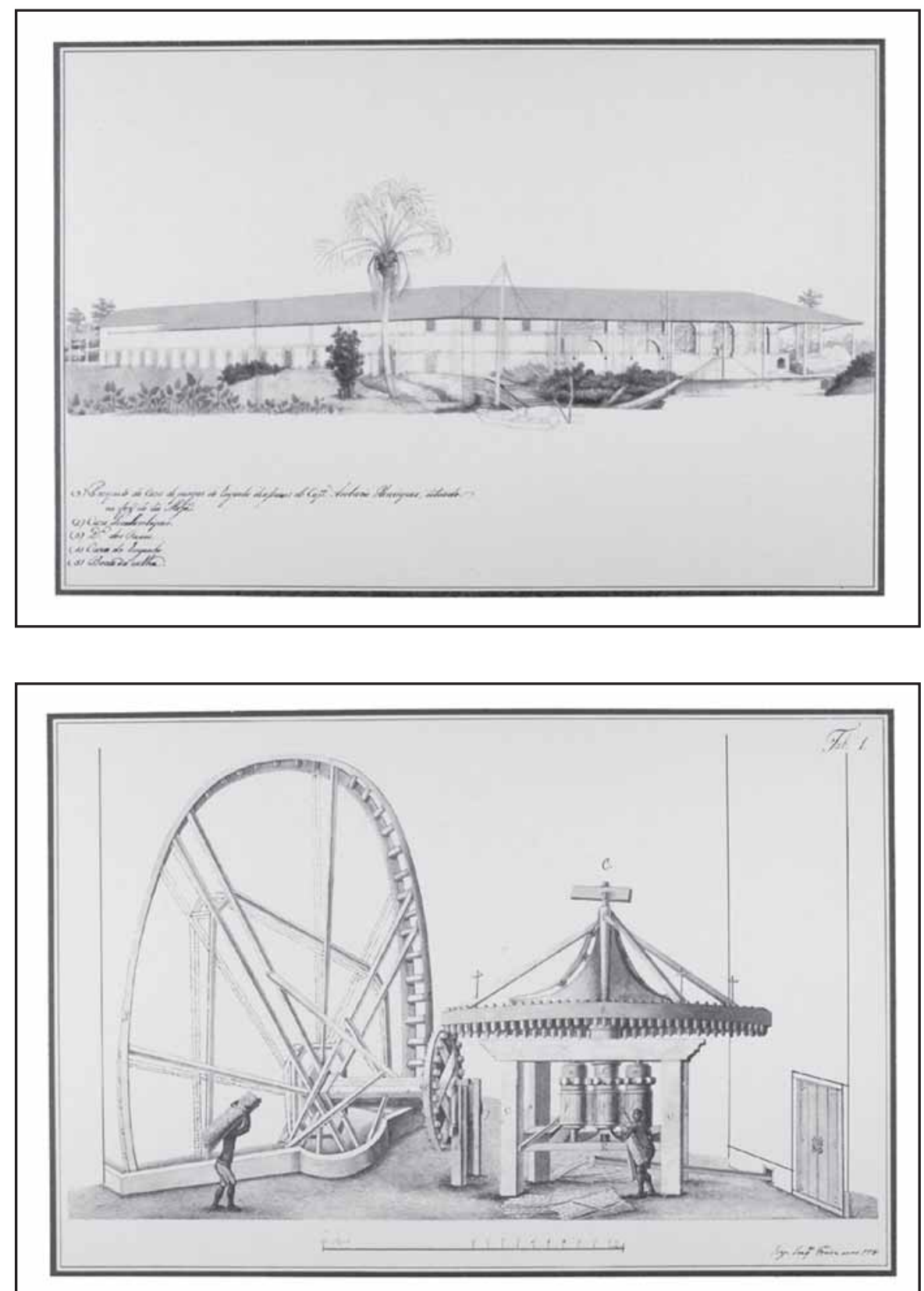

Fuente: Ferreira, Viagem. 
productores locales con la empresa monopolista. Si por un lado surgen indicios de que para algunos la compañía representó una posibilidad de crédito, barcos y otras ventajas, por otro el endeudamiento parece haber sido la tónica en las relaciones mercantiles ${ }^{62}$.

\section{El "sustento ordinario"}

Nada más dramático en el mundo colonial que la falta de víveres. En el Grão-Pará la producción de bienes para la subsistencia era también un dilema: si por un lado era evidente la necesidad de producir alimentos para la población, por otro la prioridad se dirigía hacia los negocios del interior. Para ambas tareas, el acceso a los indios era la clave segura, pero también la más compleja ${ }^{63}$.

Teóricamente, el Directorio había previsto todo lo necesario para “desterrar de las repúblicas la afición perniciosa de la ociosidad”. Los directores debían estimular a los indios de sus poblaciones a cultivar la tierra y todos debían tener rozas de yuca, maíz, arroz y fríjol, suficientes para su sustento y para atender el mercado de Belém, las tropas y el comercio de los interiores. Además, se estimulaba el cultivo de algodón y de tabaco con fines comerciales. Finalmente, el objetivo general era que cada población fuera capaz de mantenerse y además generar excedentes para colaborar con las necesidades del estado ${ }^{64}$.

La agricultura y el comercio debían ser las dos caras de una misma moneda; la misma legislación que se dirigía al montaje de una estructura fundada en las sólidas bases de la agricultura también destacaba la enorme importancia de los "negocios del interior" para el crecimiento de los ingresos del estado. Sin embargo, lo que se nota en la documentación y también en los discursos contemporáneos es que la recolección de drogas del interior sobrepasaba en ventajas al trabajo de la tierra.

No obstante, las rozas de yuca prevalecieron para la producción de harina, junto con de las de café, cacao, maíz, arroz, fríjol y tabaco. Las fuentes principales de proteínas eran el pescado y la caza, en la medida en que la cría de animales se había reducido y, por consiguiente, la falta de carne era frecuente ${ }^{65}$.

62 Otras evidencias sugieren incluso la continuidad (y hasta el crecimiento) del flujo de las exportaciones en el período posterior a la compañía, indicando que la plaza podía seguir trabajando con regularidad (deseada o posible) incluso sin las ventajas otorgadas por la corona. Antônio Carreira agrega que para valorar la importancia política, económica y financiera de la compañía se debe recordar que, a pesar de haberse extinguido en 1778, siguió comerciando "con mayor o menor amplitud hasta 1788 y su liquidación de existencias definitiva se dio solo 136 años después”. Carreira, As Compañías, 45.

63 María Yêdda Linhares asegura que el asunto en el "Gran Norte" se relaciona con los intereses y las necesidades comerciales metropolitanas que habrían provocado un desplazamiento de recursos y trabajo para las actividades de recolección de drogas del interior, más rentable que aquellas vinculadas al trabajo de la tierra, llevando los cultivos al abandono. Este argumento reitera, como la propia autora señala, formulaciones clásicas de Celso Furtado, Fernando Novais y Caio Prado Júnior. M. Yêdda Linhares, História do Abastecimento; uma problemática em questão (Brasília: Binagri, 1979), 53-54.

64 Directorio, § 16-25. 
La tortuga y el manatí eran de utilidad múltiple. Se fabricaban mantequillas para la alimentación y aceite para la iluminación a partir de la primera y mixiras del segundo. También se tomó su grasa para ser aprovechada en la culinaria. Esos alimentos, acompañados de las harinas, los vinos de frutas oleaginosas y de las variedades inagotables de pimientas, compusieron la dieta de la inmensa mayoría de la población de Grão-Pará.

Los datos disponibles muestran una agricultura generalmente limitada, dirigida prioritariamente al abastecimiento de las unidades productivas, con pocos excedentes para la comercialización. La forma de cultivo era la agricultura de coivara, usándose el sistema de reposo largo. En general, las rozas se establecieron en lugares alejados de las poblaciones. Esta práctica también ayudaba a la inestabilidad de los asentamientos poblacionales, como lo revela la correspondencia del gobernador del río Negro en 1764:

[...] no es posible hacer habitar a los indios en la población, ni conseguir de ellos que hagan las casas para que puedan vivir, porque no tienen tierras que puedan cultivar, viniendo a pernoctar en sus casas al terminar sus labores, y como tienen la posibilidad de hacer rozas del otro lado para que se puedan sustentar y como estas quedan a gran distancia, se pasan muchos meses en que no se alcanzan con la vista y por esta razón viven fuera del gremio de la Iglesia, de la verdadera disciplina y de la obediencia de vasallos ${ }^{66}$.

Es cierto que las carencias de la Capitanía de San José de Río Negro eran innumerables. Faltaban desde las harinas hasta las personas. La producción era limitada y los ingresos muy modestos. Vivían bajo un déficit crónico.

Los indios trabajadores tenían que dar cuenta de las múltiples obligaciones que tenían dentro de la estructura de la población pombalina. Según Almeida, este conjunto de tareas (canoas del interior, servicio a los moradores, rozas del común y servicio real) comprometían el tiempo necesario para que los indios se consagraran a sus propias rozas de subsistencia:

Agregando a esto su indiferencia para producir excedentes y la de los mismos directores, mucho más interesados en enviarlos al servicio de las canoas ${ }^{67}$.

65 Que esta descripción no lleve a la deducción equivocada de que la dieta de los habitantes del Grão-Pará se limitaba a harina (farinha) y pescado. Estudios contemporáneos en el área del río Vaupés (alto río Negro), hallaron 137 tipos de mandioca identificados con nombres indígenas. De estos tubérculos, domesticados a partir de una agricultura nativa de milenios de adaptación, es posible extraer una cantidad muy diversa de subproductos que multiplican las formas de preparación de los alimentos. Apenas a título de ejemplo, ténganse en cuenta los diferentes tipos de harina seca (blanca y amarilla) y de agua, beijus, carimã, manicuera, arubé, gomas, polvilhos, pós de tapioca y tucupi. En cuanto al ganado, el rebaño de la Capitanía del Río Negro era minúsculo. “¿Quién dejará de oír con asombro que en todo el río Negro portugués no hay hoy 400 cabezas de ganado vacuno?” Ferreira, Viagem, 687.

66 Citado por M. Regina Almeida, “Os Vassalos del’Rey nos Confins da Amazônia: a colonização da Amazônia Ocidental (1750-1798)” (tesis de Maestría, Universidade Federal Fluminense, Rio de Janeiro, 1990), 223-224.

67 Ibídem, 26. 
En cuanto a las rozas de los moradores, la autora asegura que no existían grandes diferencias, considerando que las técnicas de cultivo eran las mismas y también que poseían rozas localizadas en lugares distantes de las poblaciones. La distinción fundamental fue el volumen de la producción, que superaba ampliamente la de los indios.

Sin embargo, la carencia no era exclusiva de la Capitanía de Río Negro. Las poblaciones de Pará presentan un déficit todavía más profundo; mientras que en Río Negro el gasto superaba el ingreso aproximadamente en un 3,7\% en cifras globales, en las poblaciones paraenses este mismo indicador sube aproximadamente hasta el 13,8\%.

El cuadro comparativo de los ingresos de las dos capitanías permite visualizar bien esas declaraciones. Para su elaboración hemos usado los datos de la Tesorería General de Comercio de los Indios, que presenta solo el ingreso de las poblaciones bajo la protección de los directores, pero no la producción del estado en su conjunto.

Figura 7

\section{Pará y Río Negro: ingresos y gastos de las poblaciones}

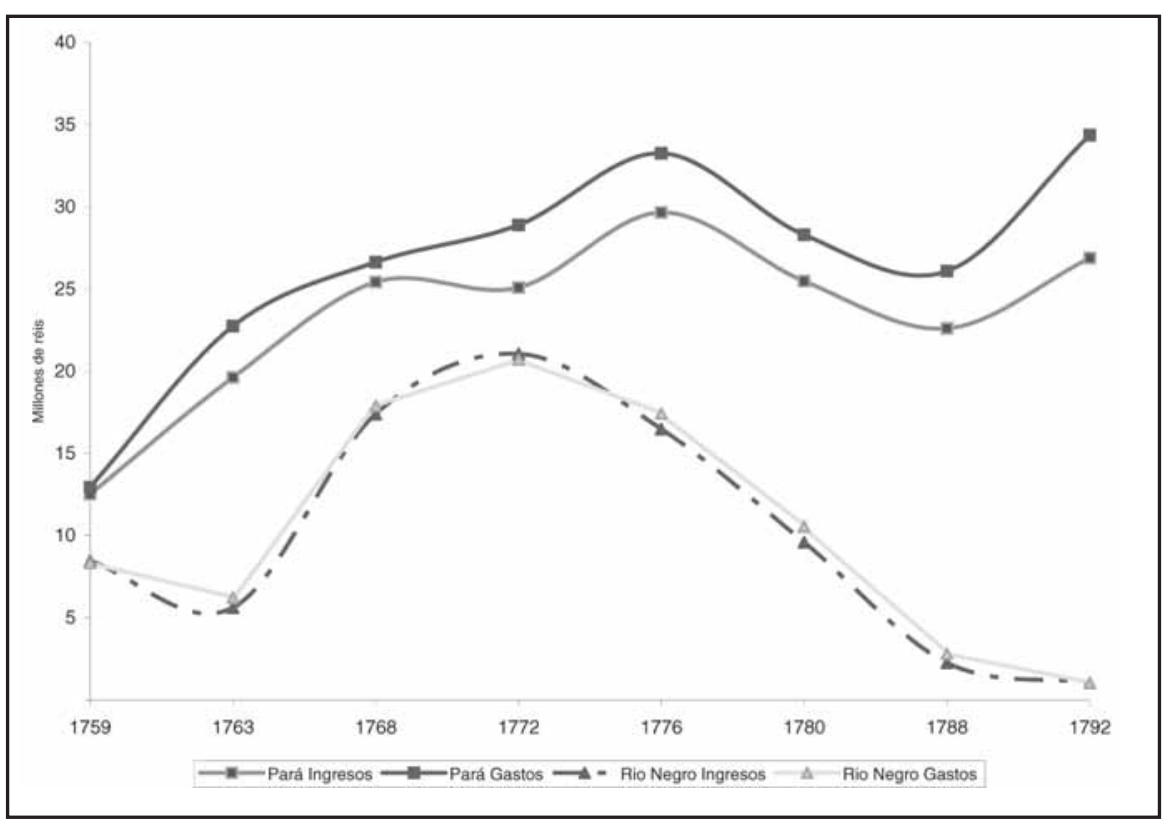

Fuente: “Mapas de Contas da Tesouraria Geral do Comércio dos Índios (1759-1792)”. MA/AHU.

Un cuadro más amplio del estado de Grão-Pará indica la existencia de una red precaria de abastecimiento, con una agricultura de subsistencia de resultados poco eficaz para atender las necesidades de comercialización. Sin embargo, observar las cifras de exportaciones del estado permite vislumbrar otras posibilidades de evaluación en cuanto 
a la producción de bienes destinados a la exportación. A pesar del predominio del cacao, el café aparece como el segundo mayor producto de exportación paraense hasta $1810^{68}$.

\section{Figura 8 \\ Productos exportados por la Compañía de Comercio del Grão Pará}

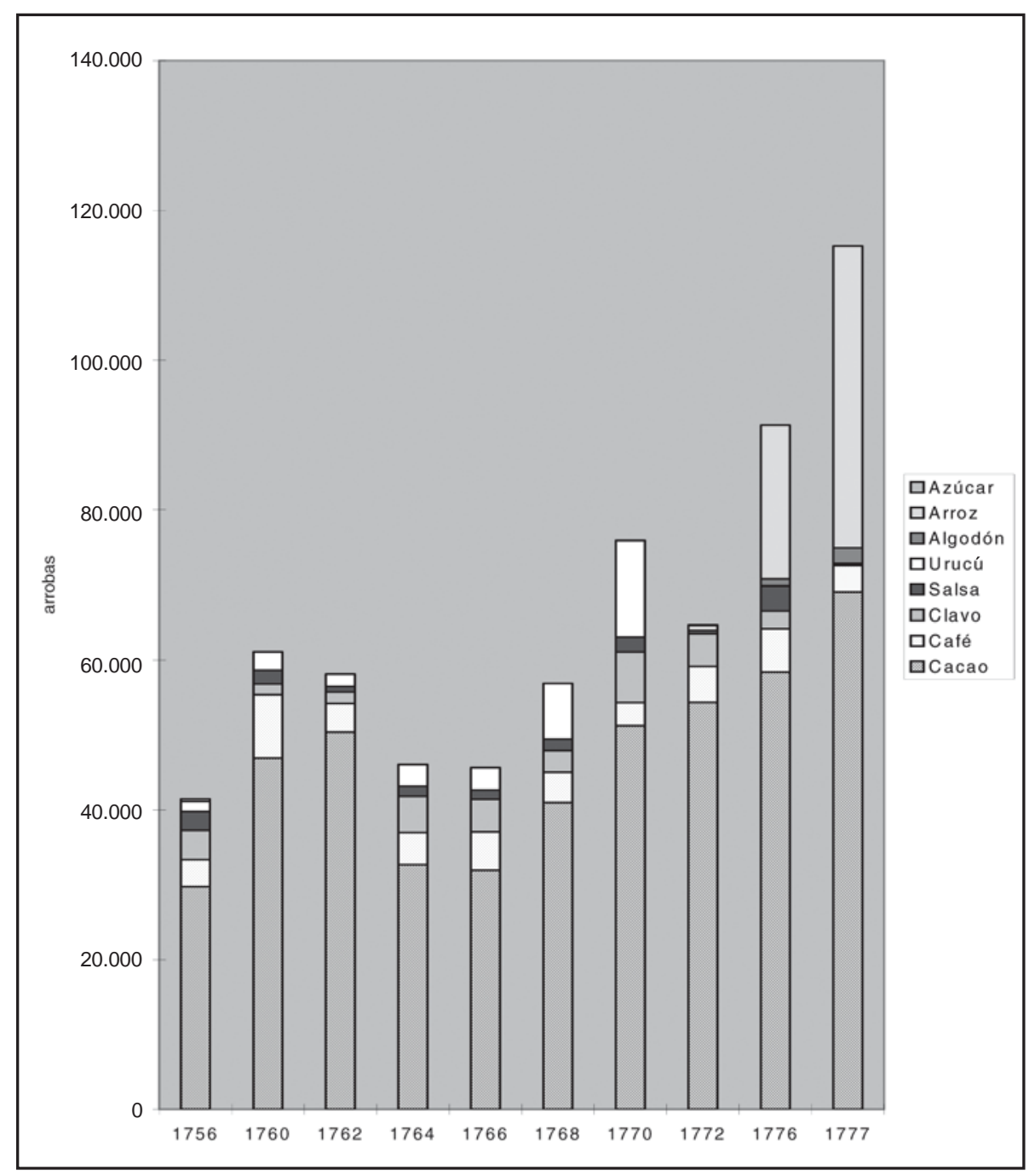

68 La presencia de algodón y de arroz no incluye las cifras de su producción en Maranhão, donde estos cultivos tuvieron una mayor penetración y un mayor desarrollo en el transcurso del siglo. Los datos hasta 1778 registran la producción de estos géneros en Grão-Pará. 
El café era un producto de exportación importante en todo el estado de GrãoPará, cultivado principalmente por los residentes en sus propiedades y en menor escala por los indios. Sin embargo, no se sembró en las rozas comunes de las poblaciones, a pesar de algunos esfuerzos aislados y poco duraderos en los pueblos del río Negro.

El gráfico de exportaciones demuestra que el cultivo del café tuvo suficiente energía como para frecuentar las líneas de exportación con cierta regularidad. En el río Negro la producción de café de los blancos era superior a la de los indios, y solo en el caso de este producto la producción de los primeros superó en 967\% la registrada para los indios ${ }^{69}$.

El asunto de la mano de obra era, una vez más, el punto neurálgico del problema de desabastecimiento crónico. Los directores fueron ampliamente responsabilizados por la decadencia de la agricultura debido a sus intereses directos en el comercio de las canoas. Los indios existentes en las poblaciones, exceptuando la parte distribuida a los moradores, debían aplicarse al beneficio y cuidado de las rozas del común, que eran las responsables de producir lo necesario para el abastecimiento de todos. Y es exactamente en este punto donde se señala el descuido de los directores.

Fundamental para mantener los poblados y también para garantizar el sustento de los indígenas recién salidos de la selva, el cultivo de la tierra y de las rozas del común adquiría importancia estratégica. Varias autoridades coloniales fueron unánimes al afirmar que los directores dieron prioridad a los interiores en detrimento de las rozas, reduciendo el número de trabajadores en las poblaciones que debían encargarse de ellas. Dentro de estos funcionarios, merecen destacarse las intervenciones de los oidores en razón de su responsabilidad como intendentes de agricultura y comercio. Estos, en su esfuerzo continuo de aplicación del Directorio, recomendaron, sugirieron y denunciaron hasta perder la esperanza. Todo parecía inocuo. Por lo que se infiere de sus discursos, las poblaciones vivían al borde de la inanición. Quizá algo cerca ella. El estado de pobreza de la mayoría de los habitantes de Grão-Pará está presente en muchos indicadores de la época.

En el río Negro, el oidor Pereira da Costa fue el primero en destacar la relación existente entre la negligencia de los directores y el desabastecimiento de la capitanía, y fue todavía más lejos al sugerir que si continuaba en vigor la distribución del tiempo de trabajo de estos indios en los interiores era prácticamente imposible mantener los cultivos en las rozas de subsistencia.

${ }_{69}$ Almeida, “Os Vassalos”, 228-229. 
Estas expediciones se hacen en el mes de febrero; se recogen a finales de junio, se les da a los indios el mes de julio para el trabajo en la roza, al final de él o a comienzos de agosto, vienen a la ciudad con el negocio, de donde se recogen a sus respectivas poblaciones, ya a finales de diciembre y principios de enero, tiempo ya impropio para las rozas en razón de las lluvias ${ }^{70}$.

Aproximadamente dos décadas después, el oidor Ribeiro de Sampaio también fue contundente en sus observaciones con respecto a los directores y no los priva de responsabilidad por el estado decadente de las poblaciones ${ }^{71}$.

Existen docenas de informaciones dadas por los gobernadores y directores de las aldeas, que hablan de la falta de harinas en sus áreas y de su incapacidad para atender las demandas de las gentes recién llegadas. Las aldeas del río Blanco estudiadas por Nádia Farage son emblemáticas de esta carencia, a tal punto que João Pereira Caldas, después de tres años consecutivos enviando harinas para el río Blanco, protesta: "si en nada nos ayudan esos comedores inútiles, por lo menos que no nos quiten el mantenimiento que tanto necesitamos" 72 .

Pero los directores ambiciosos no eran los únicos que provocaban la falta de harinas en las poblaciones. Un "perniciosísimo abuso" se volvía cada vez más visible: el uso de la mandioca para la producción de aguardiente,

[...] con tanto exceso que es rara la casa donde el aguardiente no se destila, haciéndose esta culpa extensiva a los mismos blancos, lo que también resulta en gran perjuicio de la pretendida abundancia de harinas ${ }^{73}$.

Existía toda una legislación restrictiva a la producción y venta de aguardiente de caña. En 1755, Francisco Xavier de Mendonça Furtado prohibió su venta en el pueblo de Río Negro bajo penas de multa y prisión, y el Directorio también proscribió su intro-

70 Lourenço P. Costa, “Memória sobre o Governo do Rio Negro”, Boletim de Pesquisa da Cedeam (Manaus), 2 (enero-junio 1983): 45-46.

71 Francisco Ribeiro de Sampaio, As viagens do ouvidor Sampaio (Manaus: Associação Comercial do Amazonas; Fundo Editorial, 1985).

72 Citado en Nádia Farage, As Muralhas dos Sertões: os povos indígenas e a colonização do Rio Branco (Río de Janeiro: Paz \& Terra; Anpocs, 1991), 139.

73 Costa, "Memoria”, 47. João Daniel dice que había tanto aguardiente en el Amazonas como vinos en Europa, pero él mismo afirma que tres clases eran los favoritos: el de caña de azúcar, que era muy "hechicero”; el de beiju o de harina, "que era tan espirituoso que debería llamarse cáustico en lugar de aguardiente”, y uno de anacardo, menos considerado. La lista completa sería inmensa: pajuarú, caxiri, mocororó, caiçuma, destilados del cacao, el café, la naranja de la tierra, la piña, respectivamente, taperebá, y los “vinos” de bacaba: el patauá, el açaí, el umari, el buriti, etc. Daniel, Tesouro, 1: 385386, y Ferreira, Viagem, 700-701, 724-725. 
ducción en los pueblos. Parece que fueron providencias inocuas, ya que en 1786 el gobernador de Río Negro, Tinoco Valente, reiteró la prohibición y aumentó las penas ${ }^{74}$.

Las restricciones se mantuvieron hasta 1774, cuando aparentemente la administración colonial se rindió ante la dificultad de contener el uso del aguardiente y también ante la imposibilidad de controlar la producción de la bebida a partir de otras materias primas, como la harina. En este mismo año, se estableció un contrato para la venta de aguardiente que estaría bajo la responsabilidad de las cámaras, que recibirían las ganancias. El aguardiente entonces pasó a ser tolerado en algunos casos, por ejemplo como medicina y también como parte de las provisiones de las canoas.

El consumo de bebidas "espirituosas" se reporta durante todo el siglo XVIII como rasgo inseparable de la conducta desordenada de la población, pero el uso de manivas para su fabricación era ilegal, por razones que ciertamente no tenían que ver con la salud de los indios. Entre 1774 y 1775, el oidor Ribeiro de Sampaio comentaría de una manera mucho más pragmática el asunto: prohibir el aguardiente en América era como prohibir el vino en Portugal y lo máximo que se podía conseguir con este tipo de restricción era:

[...] dar motivo a contrabandos y aumentar en exceso desproporcionadísimo el valor de los géneros prohibidos, porque los géneros siempre se han de vender, como pasa con el aguardiente. Los indios [...] si no tienen aguardiente de caña, la hacen de maíz, de piña, de beijú (que es el pan de mandioca), y de otras frutas ${ }^{75}$.

El hábito de "beberse las rozas" representa una faceta interesante de la escasez de comidas, que no deja de revelar, en el fragmento que permitió iluminarse, ciertas estrategias de intervención de los propios indios en el proyecto colonial de desarrollar la agricultura.

También en Amapá la escasez de comidas era una constante en el período pombalino. Ravena ${ }^{76}$ considera que el cuadro crónico de desabastecimiento es resultado de la presión por la mano de obra y los excedentes adicionales, que acabó por crear una tensión creciente en los límites de reproducción de esa nueva estructura económica. Pero esta situación no era exclusiva de Grão-Pará; en la capitanía de Goiás y de Ceará, la escasez de alimentos fue frecuente en las poblaciones formadas al amparo del Directorio. Este es un rasgo común en las aldeas nacidas en dicho contexto: su

74 La prohibición no fue exclusiva de Grão-Pará. Las restricciones abarcan más y parecen remontarse al comienzo del siglo XVIII cuando, a través de una provisión del Consejo Ultramarino de 1706, se estableció que cada dueño de plantación que convirtiera su caña en aguardiente perdería la cosecha y, si reincidía, sería arrestado y perdería el ingenio.

75 F. R. de Sampaio, “Notas ao papel que tem por título”, 21.

76 Nírvia Ravena, “Abastecimento: Falta e Escassez do `pão ordinário’, em Vilas e Aldeias do GrãoPará” (tesis de Maestría, NAEA/UFPA, Belém, 1994). 
incapacidad de crear, en el ámbito de la producción, una infraestructura que les garantizara su reproducción interna ${ }^{77}$.

Con el cuadro disponible, parece lícito afirmar que la presión sobre los trabajadores para ampliar la búsqueda de drogas comprometió el tiempo, los recursos y la mano de obra necesaria para los trabajos de la agricultura. En el límite, esta presión fue la que provocó las crisis de abastecimiento.

\title{
Conclusión: lucha contra el "diluvio de miseria"
}

\author{
Miré esta ciudad, \\ y vi el diluvio de miserias y pobreza \\ en que flotaba una gran parte \\ de sus habitantes $[\ldots]$ \\ Fray Caetano Brandão, Obispo de Pará \\ Siendo pues el remedio de los moradores \\ las misiones en el abastecimiento de víveres, \\ cuanto menos sean los indios, \\ y más decaigan las misiones, \\ tanto más pobres se verán los blancos; \\ Padre João Daniel, siglo XVIII
}

En Grão-Pará funcionaba un viejo lugar común de la colonia, adaptado a los colores locales: los indios son los “pies y manos” de los residentes blancos, como afirmó el padre João Daniel. Esto era absolutamente cierto, aun después de la segunda mitad del siglo XVIII, cuando la población esclava africana empezó a adquirir mayor densidad en el área con la intensificación del tráfico a través de la Compañía de Comercio.

Analizando más detenidamente las estructuras productivas que demandaban esa mano de obra, se observa que hasta 1750 las articulaciones principales del sistema económico regional se caracterizaban por la presencia de dos sectores: el primero, dominante en la economía, basado en las actividades de extracción de la selva destinadas a la exportación y en las expediciones militares responsables por el reclutamiento de la mano de obra. El otro, subsidiario, era el sector agrícola que comprendía las propiedades que usaban el trabajo compulsivo de los indios; un sector campesino heterogéneo de pequeños propietarios o arrendatarios libres; la "brecha campesina" de los esclavos

77 Esta comprobación, bajo formas diferentes, está en Farage, As Murallas; Moreira, Índios; Marivone Chaim, Aldeamentos Indígenas (Goiás, 1749 -1811) (São Paulo: Nobel; Brasília: INL/Fundação Nacional Pró-Memória, 1983) y Almeida, “Os Vassalos”. En Goiás, véase Mary Karash, “Catequese e Cativeiro: política indigenista em Goiás, 1780-1889”, en História dos Índios no Brasil, comp. Manuela C. Cunha (São Paulo: Companhia das Letras, 1992). 
indios y, finalmente, una economía misionera. Así, la tarea de reglamentar, disciplinar y distribuir el trabajo indígena fue responsabilidad del régimen de misiones, combinada con la actuación de las tropas de guerra y rescate, generando "un campesinado indígena sedentario en una región que no había conocido tal tipo social en tiempos precolombinos"78.

Los cambios introducidos por la política pombalina en la amazonia a partir de 1750 se reflejaron en la configuración de su sistema económico, haciendo surgir en el sector dominante dos subsectores: uno constituido por las grandes propiedades que usaban esclavos negros y trabajadores indios y otro relacionado con la economía de recolección de productos de la selva con mano de obra oriunda de las poblaciones pombalinas.

La frecuente rotación legal ofrece una dimensión de la intensa e intransigente disputa en que estaban envueltos los colonos y los misioneros por la prerrogativa de la distribución de los indios. No es necesario, en ese texto, detallar esta larga batalla. Se cruzan aquí varios embates, expulsiones temporales de misioneros, revueltas de colonos, entre otras cosas. Hasta la publicación de la Ley de Libertades (1755) y la expulsión posterior de los jesuitas (1759), el clima de la región se mantuvo siempre tenso por cuenta de las disputas y debates que involucraron a estos agentes coloniales.

Las cifras de la población del estado siempre le preocuparon a la administración colonial. Después de todo, buena parte del éxito del proyecto pombalino dependía de la creciente agregación de la gente a las poblaciones. Sin ellos, no hubiera habido rozas, drogas y, menos todavía, nuevos descubrimientos. La revisión efectuada en la política indigenista en la nueva coyuntura del setecientos, aunque significativa, no era suficiente para superar los antagonismos provocados por el control de los indios y de los negocios del interior. Como caras de la misma moneda y el verdadero "remedio para la pobreza”, también durante la segunda mitad del siglo XVIII, los indios disponibles eran la clave más segura para el acceso a los interiores del cacao, del clavo, del perejil y de más indios.

De manera que, revisando los datos relativos al sustento de las poblaciones, ciertas dudas permanecen: si es correcto pensar que fue la presión de las drogas lo que llevó al desabastecimiento y, considerando que su extracción está presente como actividad económica principal prácticamente desde el principio de los asentamientos portugueses en el área, se debería concluir que todo el período colonial estuvo marcado por esta característica y, de esta manera, no habría habido ningún momento sin que se viviera en una coyuntura de escasez.

Si la escasez fue tan permanente, ¿no sería más correcto considerarla como estructural? En otros términos, ¿¿no sería más acertado aprehenderla como un elemento de la misma dinámica interna regional, una variable más para entender el proceso de acu-

78 Ciro Flamarion Cardoso, Economia e sociedade em áreas coloniais periféricas: Guiana Francesa e Pará (1750-1817) (Rio de Janeiro: Graal, 1984). 
mulación interna que se hizo visible en la segunda mitad del siglo XVIII, cuando se realiza una transición (parcial) de la mano de obra indígena hacia la mano de obra esclava de origen africano?

La escasez de alimentos, evidente en los pueblos de Grão-Pará y en el discurso fragmentado del obispo Brandão, podría ser simplemente una fase (visible y dolorosa para la mayoría) de los mecanismos de control de la mano de obra y, en el límite, del propio proceso de acumulación. En esa dirección, pensamos de una manera más específica en la cuestión planteada por John Monteiro y C. MacLachlan, según la cual el acceso seguro a los indios era la garantía de formación y de consolidación de las fortunas y de las jerarquías locales, al mismo tiempo que ampliaba la distancia entre unos pocos afortunados y la mayoría de la población, inmersa en una gran pobreza.

Así, aquellos que estaban a salvo del “diluvio de pobreza en que flotaba la mayoría”, tenían garantizado su acceso a los interiores de las drogas y a los indios, a los trabajadores necesarios para las faenas agrícolas, a los remeros, pescadores, cazadores, carpinteros, alfareros, a los sirvientes domésticos, amas de leche, lavanderas, sirvientas, cocineros, hilanderas, con un costo reducido que, en último análisis, les permitió acumular lo suficiente como para adquirir "piezas de África” a partir de la instalación de la Compañía de Comercio e incluso disfrutar de ciertas facilidades de crédito concedidas a los que se presentaran para la compra de esclavos. Frente a los datos, podemos concluir que también en la amazonia portuguesa el único y cierto remedio contra la pobreza eran los indios.

\section{Bibliografía}

\section{Fuentes primarias}

Archivo Nacional de Río de Janeiro.

Biblioteca Nacional de Río de Janeiro.

\section{Fuentes secundarias}

Alden, Dauril. O significado da produção de cacau na região amazônica no fim do período colonial: um ensaio de história econômica comparada. Belém: Núcleo de Altos Estudos Amazônicos - NAEA/UFPA, 1974.

Almeida, M. Regina. “Os Vassalos del’Rey nos Confins da Amazônia: a colonização da Amazônia Ocidental (1750-1798)”. Tesis de maestría, Universidade Federal Fluminense, Rio de Janeiro, 1990.

Amazonas, Lourenço Araújo. Dicionário Topográfico, Histórico, Descritivo da Comarca do Alto Amazonas. Manaus: Associação Comercial do Amazonas/Fundo Editorial, 1982. 
Amoroso, Marta. “Guerra Mura no século XVIII: versos e versões”. Tesis de maestría, Unicamp, São Paulo, 1991.

Azevedo, João Lúcio. Os Jesuítas no Grão-Pará. Coimbra: Imprensa da Universidade, 1930. . Estudos de História Paraense. Belém: Secult, 1994.

Belloto, Heloísa. "Pombal - Marquês de”. En Dicionário da História da Colonização Portuguesa no Brasil, ed. Beatriz N. Silva, 645-648. Lisboa: Verbo, 1994.

Boxer, Charles. O Império Colonial Português, 1415 - 1825. Lisboa: Edições 70, 1981.

Cardoso, Ciro Flamarion. Economia e sociedade em áreas coloniais periféricas: Guiana Francesa e Pará (1750-1817). Rio de Janeiro: Graal, 1984.

Carreira, Antônio. As Companhias Pombalinas de Navegação, Comércio e Tráfico de Escravos entre a Costa Africana e o Nordeste Brasileiro. Lisboa, 1969.

Chaim, Marivone. Aldeamentos Indígenas (Goiás, 1749 -1811). São Paulo: Nobel; Brasília: INL/Fundação Nacional Pró-Memória, 1983.

Costa, Lourenço P. "Memória sobre o Governo do Rio Negro”. Boletim de Pesquisa da Cedeam (Manaus), 2 (enero-junio 1983): 45-46.

Daniel, João. Tesouro Descoberto no Rio Amazonas. 2 t. Vol. 95. Rio de Janeiro: Separata dos Anais da Biblioteca Nacional, 1976.

Davidson, David. "Rivers \& Empires: the Madeira Route and Incorporation of the Brazilian Far West, 1737-1808”. Tesis de doctorado, Yale University, 1970.

Dias, Manuel Nunes. Fomento e Mercantilismo: a Companhia Geral do GrãoPará e Maranhão (1755-1778). 2 t. Belém: UFPA, 1970.

Domingues, Ângela. “As sociedades e as culturas indígenas face à expansão territorial luso-brasileira na segunda metade do século XVIII”. En Brasil nas vésperas do Mundo Moderno, 183-207. Lisboa: Comissão Nacional para as Comemorações dos Descobrimentos Portugueses, 1992.

Farage, Nádia. As Muralhas dos Sertões: os povos indígenas e a colonização do Rio Branco. Rio de Janeiro: Paz \& Terra/Anpocs, 1991. 
Ferreira, Alexandre R. Viagem Filosófica ao Rio Negro. Belém: MPEG/CNPq, 1983. - Viagem Filosófica às Capitanias do Grão-Pará, Rio Negro, Mato Grosso e Cuiabá. Vol. 1. São Paulo: Brunner, 1970.

Hemming, John. Amazon Frontier. The Defeat of the Brazilian Indians. London: Macmillan, 1987.

Holanda, Sérgio B. de. Monções. São Paulo: Brasiliense, 1990.

Karash, Mary. “Catequese e Cativeiro: política indigenista em Goiás, 1780-1889”. En História dos Índios no Brasil, comp. Manuela C. Cunha. São Paulo: Companhia das Letras, 1992.

Lapa, J. R. Amaral. "Do Comércio em Área de Mineração”. En Economia Colonial, 15-110. São Paulo: Perspectiva, 1973.

Linhares, M. Yêdda. História do Abastecimento; uma problemática em questão. Brasília: Binagri, 1979.

MacLachlan, Colin. "Indian Labor Structure in the Portuguese Amazon, 1700-1800”. En Colonial Roots of Modern Brazil, comp. Dauril Alden. Berkeley: University of California Press, 1973.

Maxwell, Kenneth. Marquês de Pombal: paradoxo do Iluminismo. Rio de Janeiro: Paz \& Terra, 1996.

Mendoça, Marcos. Amazônia na Era Pombalina: correspondência inédita do governador e capitão-general do Estado do Grão-Pará e Maranhão, Francisco Xavier de Mendonça Furtado, 1751-1759. 3 t. Río de Janeiro: IHGB, 1963.

Monteiro, John. Negros da Terra: índios e bandeirantes nas origens de São Paulo. São Paulo: Companhia das Letras, 1994.

. "Sal, Justiça Social e Autoridade Colonial”. Comunicación presentada a la XXI Reunión de la Latin American Studies Association-LASA, Chicago, 1998.

Moraes, A. J. Mello. Corographia Historica, Chronographica, Genealogica, Nobiliaria e Politica do Imperio do Brasil. Río de Janeiro: Typographia Americana, 1858-1860. 
Moreira Neto, Carlos A. "Política indigenista brasileira durante o século XIX”. Tesis doctoral, Rio Claro, SP., 1971.

. Índios da Amazônia: de maioria a minoria (1750-1850). Petrópolis: Vozes, 1998.

Ravena, Nírvia. “Abastecimento: Falta e Escassez do "pão ordinário” em Vilas e Aldeias do Grão-Pará”. Tesis de maestría, NAEA/UFPA, Belém, 1994.

Reis, Arthur. Aspectos da Experiência Portuguesa na Amazônia. Manaus: Governo do Estado, 1966.

Sampaio, Francisco Ribeiro de. "Notas ao papel que tem por título, Memória sobre o Governo do Rio Negro". Boletim de Pesquisa da CEDEAM (Manaus), 2, núm. 3 (julio-diciembre 1983) y núm. 4 (enero-diciembre 1984).

. As viagens do ouvidor Sampaio. Manaus: Associação Comercial do Amazonas; Fundo Editorial, 1985.

Sampaio, Patrícia M. "Espelhos Partidos: Etnia, legislação e desigualdade na colônia. Sertões do Grão-Pará, c. 1755 - c. 1823”. Tesis de doctorado, Universidade Federal Fluminense, Rio de Janeiro, 2001.

Santos, Francisco J. Além da conquista: guerras e rebeliões indígenas na Amazônia pombalina. Manaus: Universidade do Amazonas, 1999.

São José, Fr. João de. "Viagem e Visita do Sertão em o Bispado do Gram-Pará em 1762 e 1763”. Revista do Instituto Histórico e Geográfico Brasileiro (Río de Janeiro), 9 (1847): 43-107, 199-227, 328-375, 476-527.

Schwartz, Stuart B. Segredos Internos. São Paulo: Companhia das Letras, 1988.

Spix, Johann B. von y Karl F. P. von Martius. Viagem pelo Brasil (1817-1820). 3 vol. Belo Horizonte: Itatiaia; São Paulo: Edusp, 1981. 
Figura 9

Telar de las indias de Monte Alegre para la fabricación de redes (1785)

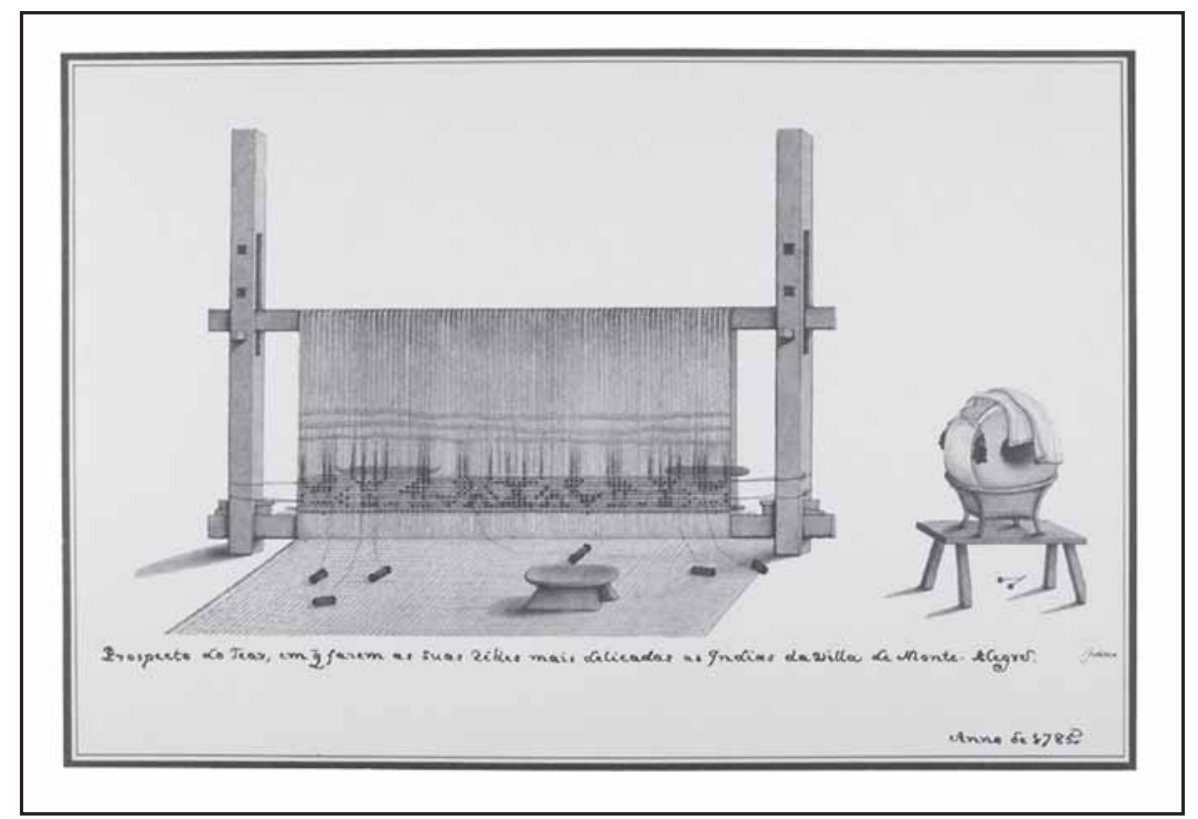

Fuente: Ferreira, Viagem. 